\title{
Análisis filogenético del género Mimon Gray, 1847 (Mammalia, Chiroptera, Phyllostomidae) con la descripción de un nuevo género
}

\author{
Natali Hurtado ${ }^{1,2^{*}}$ y Víctor Pacheco ${ }^{2,3}$
}

Introduction: Mimon is currently considered a monophyletic genus that comprises two subgenera: Mimon (represented by M. bennettii and M. cozumelae), and the taxon formerly named "Anthorhina" (represented by $M$. crenulatum and M. koepckeae). However, recent molecular phylogenies show Mimon as a polyphyletic genus within Phyllostomidae.

Methods: Herein, we present a phylogenetic approach based on morphology, which includes all species of the genus Mimon, with emphasis on geographical populations of $M$. crenulatum. Our data matrix was built with our own examination of M. bennetti $(n=5)$, M. cozumelae $(n=31)$, M. crenulatum $(n=181)$, and M. koepckeae $(n=3)$ for 91 morphological characters including external, skull-dental and postcraneal traits. The species Lophostoma occidentalis, Trachops cirrhosus, Tonatia saurophila, Phyllostomus discolor, Phylloderma stenops, and Micronycteris megalotis were selected as outgroups. The tree was rooted on M. megalotis. An exhaustive search with 135 unordered characters was performed to find the most parsimonious trees.

Results: A single well-supported tree of 306 steps was obtained. Bootstrap and Jacknife with 10,000 resampling were used as support estimators. The most parsimonious tree confirms Mimon is a polyphyletic genus, where the subgenus Mimon and the taxon formerly named "Anthorhina" are strongly supported but unrelated monophyletic groups.

Discussion and conclusions: In order to solve this taxonomic problem, we recommend the taxon formerly named "Anthorhina" be raised at genus level, but with a new name because "Anthorhina" is a synonym of Tonatia. Finally, we provide an emended diagnosis of Mimon s.s. and the description of a new genus, based on morphological characters used for the phylogeny.

Key words: Gardnerycteris nov. gen., morphological, maximun parsimony.

\section{Resumen}

Mimon es considerado actualmente un género monofilético conformado por dos subgéneros: Mimon (representado por M. bennettii y M. cozumelae), y el taxón anteriormente llamado "Anthorhina" (representado por M. crenulatum y M. koepckeae). Sin embargo, los recientes resultados de estudios filogenéticos moleculares indican que Mimon es un género parafilético dentro de Phyllostomidae. En el presente estudio se realizó una revisión de

'Doctorado en Ciencias, Mención Ecología y Evolución, Facultad de Ciencias, Universidad Austral de Chile, Valdivia, Chile. Edificio Pugin s/n, Instituto de Ciencias Ambientales y Evolutivas, Universidad Austral de Chile. E-mail: natalihm@gmail.com $(\mathrm{NH})$.

²Departamento de Mastozoología, Museo de Historia Natural de la Universidad Nacional Mayor de San Marcos, Lima, Perú. $(\mathrm{NH})$.

${ }^{3}$ Instituto de Ciencias Biológicas "Antonio Raimondi", Facultad de Ciencias Biológicas, Universidad Nacional Mayor de San Marcos, Lima, Perú. E-mail: vpachecot@unmsm.edu.pe (VP).

${ }^{*}$ Corresponding author 
caracteres morfológicos de todas las especies de Mimon, con énfasis en las poblaciones de $M$. crenulatum, construyendo una matriz a partir de 91 caracteres de la morfología externa, cráneo-dental y postcraneal. Las especies Lophostoma occidentalis, Trachops cirrhosus, Tonatia saurophila, Phyllostomus discolor, Phylloderma stenops y Micronycteris megalotis fueron elegidas como grupo externo, de las cuales $M$. megalotis fue usada para el enraizamiento. Se realizó una búsqueda exhaustiva para encontrar el mejor árbol a partir de 135 caracteres no ordenados, que incluyen los caracteres descritos en este estudio y los caracteres del aparato hioideo, lengua, tracto digestivo y reproductivo y cerebro, tomados de Wetterer et al. (2000). Se obtuvo un único árbol más parsimonioso bien soportado de 306 pasos. El soporte de las ramas fue pesado con Bremer y el remuestreo por Bootstrap y Jacknife con 10,000 réplicas. El árbol más parsimonioso confirma que Mimon es polifilético donde los subgéneros y el taxón anteriormente llamado "Anthorhina" están fuertemente respaldados en nodos no relacionados. Con la finalidad de resolver el surgente problema taxonómico, recomendamos elevar al taxón anteriormente llamado "Anthorhina" a género. Dado que "Anthorhina" es sinónimo de Tonatia, se propone un nuevo nombre. Finalmente, brindamos las diagnosis corregidas de Mimon s.s. y del nuevo género Gardnerycteris, basadas en los caracteres usados en el análisis filogenético.

Palabras clave: Gardnerycteris nov. gen., morfológico, máxima parsimonia.

El género Mimon Gray, 1847 es un miembro de la familia Phyllostomidae - la familia más diversa de Sudamérica (Jones y Carter 1976; Gardner 2008)- dentro de la subfamilia Phyllostominae (Wetterer et al. 2000; Baker et al. 2003; Simmons 2005; Williams y Genoways 2008). Phyllostominae presenta la costilla de la hoja nasal extendida hasta el margen superior del limbo y nasales conectados con las cavidades orales por el hueso nasopalatino a través de los forámenes incisivos como sinapomorfías (Wetterer et al. 2000), además de presentar las hojas nasales bien definidas, molares dilambodontes y uropatagio bien desarrollado (Williams y Genoways 2008).

Mimon incluye especies de tamaño mediado y grande, caracterizadas por exhibir un solo incisivo superior, dos premolares inferiores, protuberancias del mentón divididas por un surco medio, hojas nasales largas, plagiopatagio inserto en el tobillo, patas largas, cola extendida hasta la mitad del uropatagio y calcar más largo que la pata (Gray 1847; Williams y Genoways 2008). Asimismo, Mimon fue considerado monofilético por presentar vibrisas interramales y la ausencia del incisivo externo inferior como sinapomorfías del género (Wetterer et al. 2000).

Mimon comprende dos subgéneros y cuatro especies (Simmons 2005). El subgénero Mimon incluye M. bennettii (Gray 1838) y M. cozumelae Goldman 1914, y el subgénero anteriormente llamado "Anthorhina" incluye a M. crenulatum (E. Geoffroy St.-Hilaire 1803) y M. koepckeae Gardner y Patton 1972. Mimon bennettii se distribuye desde el sur de Venezuela y Colombia y el norte de las Guayanas hasta el sur de Brasil (Williams y Genoways 2008; Gregorin et al. 2008); M. cozumelae desde el sur de México hasta el noroeste de Colombia (Simmons y Voss 1998; Gregorin et al. 2008; Williams y Genoways 2008); M. crenulatum desde el sur de Panamá, noreste de Venezuela y Ecuador y norte del Perú hasta el norte de Bolivia y sur de Brasil (Koopman 1978; Williams y Genoways 2008); y M. koepckeae solo en la vertiente oriental de los Andes centrales de Perú (Gardner y Patton 1972; Koopman 1978; Hurtado et al. 2014). 
La validez de los taxones asignados a Mimon ha sido ampliamente discutida. El taxón anteriormente llamado "Anthorhina" ha sido considerado como un sinónimo (Simpson 1945; Handley 1960) o como un subgénero de Mimon (Cabrera 1958; Goodwin y Greehall 1961; Koopman 1993, 1994; Wetterer et al. 2000; Simmons 2005); o un género (Miller 1907; Husson 1962). Sin embargo, independientemente de la jerarquía taxonómica, Anthorhina debe ser usado como un sinónimo menor de Tonatia, ya que comparten el mismo espécimen tipo con Tonatia bidens (Gardner y Ferrel 1990; Simmons 2005). Por lo que el taxón anteriormente llamado "Anthorhina" no debe usarse en un contexto taxonómico (Simmons 2005; Williams y Genoways 2008).

Respecto a las especies, Mimon cozumelae fue tratada como un sinónimo (Handley 1960; Ortega y Arita 1997) o una subespecie de M. bennettii (Koopman 1978; 1993; 1994). Sin embargo ambas entidades han sido reconocidas como especies plenas con fuerte respaldo morfológico (Simmons y Voss 1998; Simmons 2005; Gregorin et al. 2008; Williams y Genoways 2008). Por otra parte, algunas poblaciones de M. bennettii distribuidas al noreste de Brasil corresponderían a una especie nueva aún no descrita (Ortega y Arita 1997; Williams y Genoways 2008). Mimon crenulatum comprende cuatro subespecies: crenulatum, longifolium, picatum y keenani (Handley 1960; Simmons 2005; Williams y Genoways 2008); de las cuales picatum podría ser un sinónimo de M. crenulatum (Handley 1960); asimismo, Cadenillas (2010) sugirió que la población de M. crenulatum keenani distribuida en la vertiente occidental de los Andes podría ser elevada a especie después de una revisión de éstas poblaciones. Por último, M. koepckeae fue considerada una subespecie de M. crenulatum (Koopman 1976, 1978, 1993, 1994). Esta posición fue desestimada por Simmons y Voss (1998), Simmons (2005) y Williams y Genoways (2008) al considerar válidos los argumentos de Gardner y Patton (1972). Complementariamente, Hurtado et al. (2014) respaldaron la validez de M. koepckeae con nueva evidencia morfológica.

La posición filogenética de Mimon en los Phyllostomidae ha sido abordada en numerosos estudios (i. e. Patton y Baker 1978; Van Den Bussche 1989; Wetterer et al. 2000; Baker et al. 2000, 2003; Dávalos et al. 2012). En ese sentido, Patton y Baker (1978), basados en caracteres cromosómicos, consideraron a M. crenulatum como grupo hermano de Phyllostomus. Van Den Bussche (1989), usando caracteres moleculares (sititos de restricción del rRNA), definió el grupo Phyllostomus, integrado por Phyllostomus, Tonatia, Lonchorhina y Mimon crenulatum. Wetterer et al. (2000), basados en caracteres morfológicos, cromosómicos sexuales y moleculares (sitios de restricción del rRNA y el gen satelital EcoRI), consideraron a Mimon monofilético y grupo hermano de Lonchorhina y Macrophyllum. Paralelamente, Baker et al. (2000), basados en caracteres moleculares (gen nuclear RAG2), ubicaron a M. crenulatum como grupo hermano de Phylloderma. Poco después, Baker et al. (2003) adicionaron secuencias mitocondriales ribosómicas (12S y $16 \mathrm{~S}$ del RNAr y RNAt Val), ubicando a Mimon crenulatum como grupo hermano de Phyllostomus, dentro de la tribu Phyllostomini junto con Phylloderma, Lophostoma y Tonatia.

Recientemente, Dávalos et al. (2012) analizaron las relaciones filogenéticas de la familia Phyllostomidae, basados en caracteres morfológicos y secuencias de DNA mitocondriales y nucleares empleados anteriormente (V. gr. Van Den Bussche 1989; Baker et al. 2000, 2003; entre otros), añadiendo nuevos datos morfológicos y moleculares, encontrando a Mimon como un género polifilético en análisis de máxima parsimonia para caracteres morfológicos, máxima verosimilitud para caracteres moleculares e Inferencia Bayesiana 
para datos combinados. Sin embargo, ninguno de los estudios mencionados ha incluido todas las especies de Mimon para explorar las relaciones filogenéticas dentro del género.

Finalmente, Hurtado et al. (2014), basados en comparaciones morfológicas de las cuatro especies de Mimon, resaltaron que existen suficientes caracteres en el taxón anteriormente llamado "Anthorhina" que lo distinguen de los descritos para Mimon por Gray (1847); por lo que sugieren realizar estudios filogenéticos del género que incluyan a todas las especies que lo conforman.

En este trabajo presentamos una aproximación a las relaciones filogenéticas entre las especies miembros de Mimon, mediante un análisis de máxima parsimonia basado en caracteres morfológicos discretos tomados de la morfología externa, cráneo-dental y postcraneal, así como los caracteres del aparato hioideo, lengua, tracto digestivo y reproductivo y cerebro, tomados de Wetterer et al. (2000). Los resultados obtenidos nos brindan una nueva interpretación acerca de la polifilia de Mimon y la monofilia del taxón anteriormente llamado "Anthorhina". Basados en la evidencia filogenética y morfológica se propone un nuevo nombre para el taxón anteriormente llamado "Anthorhina", y se proponen diagnosis corregidas de las especies del grupo interno.

Muestra taxonómica. En el presente estudio el grupo interno estuvo conformado por las cuatro especies reconocidas de Mimon en dos subgéneros: Mimon y el taxón anteriormente llamado "Anthorhina": M. bennettii $(n=5)$, M. cozumelae $(n=31)$, M. crenulatum $(n=181)$ y M. koepckeae $(n=3)$. Dentro de M. crenulatum se distinguieron los siguientes taxa, en base a subespecies y poblaciones: M. c. crenulatum de Brasil; M. c. longifolium (sensu Koopman 1978); $M$. c. keenani diferenciando las poblaciones de "Tumbes”, "Ecuador", "Venezuela” $y$ “Panamá"; y las poblaciones de $M$. crenulatum "Amazonía" para especímenes de la cuenca amazónica entre Colombia, Perú y Venezuela (Oriente); M. crenulatum "Sur" para especímenes distribuidos entre el sureste de Perú y el noroeste de Bolivia; y M. crenulatum "Guayanas" para especímenes provenientes de Trinidad y Tobago, Surinam y Guayana Francesa. No incluimos a M. c. picatum en la muestra, ya que no revisamos el espécimen tipo o topotipos (esta subespecie es sólo conocida por el espécimen tipo, sensu Handley 1960).

Selección del grupo externo. Para determinar la polaridad de los caracteres y para poner a prueba la monofilia de Mimon se usaron seis especies como grupo externo: Micronycteris megalotis (Gray 1842), Lophostoma occidentalis (W. B. Davis y Carter 1978), Trachops cirrhosus (Spix 1823), Tonatia saurophila Koopman y Williams 1951, Phylloderma stenops Peters 1865 y Phyllostomus discolor (J. A. Wagner 1843). De las cuales se enraizó el árbol con Micronycteris megalotis, por ser ancestral a todos los taxa incluidos en el estudio (Baker et al. 2003; Dávalos et al. 2012). Los géneros Phyllostomus y Phylloderma son considerados grupos hermanos de Mimon crenulatum (Patton y Baker 1978; Baker et al.2003; Dávalos et al. 2012); Trachops, Tonatia y Lophostoma están considerados dentro de la tribu Phyllostomini junto con M. crenulatum y Phyllostomus (Baker et al. 2003:22).

Muestraexaminada. Se examinaron 220 individuos adultos asignados al género Mimon, cuya edad fue determinada siguiendo a Pacheco y Patterson (1992) y Brunet-Rossinni y Wilkinson (2009). Estos especímenes están depositados en colecciones científicas de diferentes museos en forma de pieles, cráneos, esqueletos y especímenes preservados en líquido. En el Apéndice 1 se detalla el listado de los especímenes examinados y las colecciones de procedencia. 
Definición de caracteres y estados de carácter. El criterio para la definición de caracteres discretos se estableció en base a estructuras homólogas, cuando el estado del carácter estuvo presente en todos los especímenes del taxón o población examinada (Wiens 2000). Los caracteres continuos, tomados de las medidas corporales registradas en etiquetas de los especímenes, y directamente de la longitud del pelaje (calibrador de $\pm 0.01 \mathrm{~mm}$ ), fueron convertidos a caracteres discretos cuando éstos no mostraron sobreposición de rangos (Wiens 2000). Se definió 91 caracteres morfológicos discretos e independientes en total, de los cuales 43 corresponden a la morfología externa, 44 a caracteres cráneo-dentales y 4 a caracteres postcraneales. Adicionalmente, se incorporaron 44 caracteres del aparato hioideo, lengua, tracto digestivo y reproductivo y cerebro tomados de Wetterer et al. (2000) sin modificaciones en los estados. Del total de caracteres $58 \%$ corresponde a caracteres binarios y $42 \%$ a caracteres multiestado. Estos caracteres incluyen autapomorfias, ya que son necesarias para la diagnosis de los taxa. Las entradas faltantes fueron codificadas con "?" y los estados inaplicables con "-" (Weterer et al. 2000).

Método para el análisis filogenético. La matriz de datos se ingresó en una hoja de cálculo de Excel, que fue transformada a texto con los parámetros de ejecución de lectura para el programa TNT (Goloboff et al. 2008). El análisis filogenético y el cálculo del soporte de ramas fueron realizado usando TNT (Goloboff et al. 2008), en una Macintosh Mac OS X 10.8.2.

Se realizó una búsqueda exhaustiva del árbol más parsimonioso, tratando a todos los caracteres como no ordenados. El soporte de ramas fue calculado realizando Bootstrap y Jacknife de frecuencias relativas con 10,000 réplicas por cada tipo de remuestreo; por cada réplica se realizaron 10 adiciones por secuencia y se retuvo 1,000 árboles por réplica. Asimismo, se realizó un análisis de Bremer para pesar el soporte de ramas. En el apéndice 2 se presenta un listado de la optimización de sinapomorfías para los nodos obtenidos.

Descripción de caracteres

Morfología externa. Carácter 1. Longitud total: LT grande $>95 \mathrm{~mm}(0)$; o LT pequeño $<90 \mathrm{~mm}$ (1). Son pequeños todos los miembros del subgénero anteriormente llamado "Anthorhina", así como Lophostoma occidentalis y Micronycteris megalotis. Son grandes los integrantes del subgénero Mimon, Phylloderma stenops, Phyllostomus discolor, Tonatia saurophila y Trachops cirrhosus. Carácter usado por primera vez en una filogenia.

Carácter 2. Patrón de bandas de contraste del pelaje dorsal: unicoloreado (0); o bicoloreado, pelos de bases claras y puntas oscuras (1); o tricoloreado, pelos con bases blanquecinas, banda media pálida y puntas oscuras (2). El estado unicoloreado es definido cuando sólo se aprecia un solo color desde la base hasta la punta del pelo; bicoloreado cuando se observan un tono en la mitad basal y otro en la mitad apical; y tricoloreado cuando se observan un tono en la parte basal, otro contrastante en la parte media y un tono contrastante con el anterior en la parte apical. El pelaje dorsal es unicoloreado en M. C. crenulatum, M. c. longifolium, M. crenulatum "Sur", M. crenulatum "Amazonía" y M. crenulatum "Guayanas"; es bicoloreado en M. koepckeae, M. c. keenani, Tonatia saurophila, Trachops cirrhosus y Micronycteris megalotis; es tricoloreado en los integrantes del subgénero Mimon, Phylloderma stenops, Phyllostomus discolor y Lophostoma occidentalis. Carácter usado por Wetterer et al. (2000; carácter 5) y Velazco (2005; carácter 13).

Carácter 3. Apariencia de la línea dorsal: ausente (0); delgada y tenue (1); o gruesa y definida (2). La línea dorsal es gruesa y bien definida en $M$. crenulatum keenani; la línea 
dorsal es variable, siendo entre delgada y tenue en los representantes de M. c. crenulatum, M. c. longifolium, M. crenulatum "Sur", M. crenulatum "Amazonía", M. crenulatum "Guayanas". La línea dorsal es ausente en M. koepckeae, el subgénero Mimon, Phylloderma stenops, Phyllostomus discolor, Lophostoma occidentalis, Tonatia saurophila, Trachops cirrhosus y Micronycteris megalotis. Carácter usado por Wetterer et al. (2000; carácter 7) y Velazco (2005; carácter 11).

Carácter 4. Longitud del pelaje dorsal: largo $>8 \mathrm{~mm}(0)$; o mediano en un rango de 6.5 a $7.5 \mathrm{~mm}$ (1); o corto $<6 \mathrm{~mm}$ (2). La longitud del pelaje dorsal, se define por el largo de los pelos a la altura de la rabadilla. Es corto en los representantes de M. c. crenulatum, M. crenulatum "Amazonía", M. crenulatum"Guayanas", Phylloderma stenops y Phyllostomus discolor; es mediano en M. koepckeae, M. c. keenani, M. c. longifolium, M. crenulatum "Sur" y Lophostoma occidentalis; es largo en el subgénero Mimon, Tonatia saurophila, Trachops cirrhosus y Micronycteris megalotis. Carácter usado por Velazco (2005; carácter 12).

Carácter 5. Patrón de bandas de contraste del pelaje ventral: unicoloreado (0); bicoloreado (1); o tricoloreado (2). El estado unicoloreado se define cuando se aprecia un solo color en todo el pelo, bicoloreado cuando se aprecian dos colores contrastantes en cada mitad del pelo, y tricoloreado cuando se aprecian tres bandas de colores contrastantes entre una y la anterior. El pelaje ventral es bicoloreado en M. koepckeae, M. crenulatum "Sur", Tonatia saurophila; es tricoloreado en todas las poblaciones de M. c. keenani, M. c. longifolium, M. c. crenulatum, M. crenulatum "Amazonía", M. crenulatum "Guayanas", Phylloderma stenops, Phyllostomus discolor, Lophostoma occidentalis; y unicoloreado en el subgénero Mimon, Trachops cirrhosus y Micronycteris megalotis. Usado por Velazco (2005; carácter 14) con un cuarto estado: tetracoloreado.

Carácter 6. Densidad del pelaje corporal: denso (0); o laxo (1). La densidad del pelo fue definida por la cobertura de la piel en el lomo, siendo denso cuando la piel estuvo cubierta completamente por los pelos y laxo cuando se observa exposición de piel. El pelaje corporal es denso en M. koepckeae, M. crenulatum "Sur", Phyllostomus discolor y Micronycteris megalotis. En M. c. crenulatum, M. c. longifolium, M. c. keenani, M. crenulatum "Amazonía", M. crenulatum "Guayanas", el subgénero Mimon, Phylloderma stenops, Lophostoma occidentalis, Tonatia saurophila y Trachops cirrhosus el pelaje es laxo. Carácter usado por primera vez en una filogenia.

Carácter 7. Densidad de los pelos en el hocico: desnudo (0); o no desnudo (1). El estado desnudo se define cuando el hocico exhibe escasos pelos cortos, claros y esparcidos; es no desnudo cuando el hocico no deja piel expuesta, está cubierto de pelos largos, oscuros y densos. En todos los representantes del subgénero anteriormente llamado "Anthorhina", Lophostoma occidentalis y Trachops cirrhosus el hocico exhibe escasos pelos cortos, ubicados esparcidamente dando la apariencia de desnudez. En el subgénero Mimon, Phylloderma stenops, Phyllostomus discolor, Tonatia saurophila y Micronycteris megalotis el hocico exhibe abundantes pelos largos que cubren toda la piel. Carácter usado por primera vez en una filogenia.

Carácter 8. Número de vibrisas laterales a la hoja nasal: 5 vibrisas por lado (0); o 6 vibrisas por lado (1); o 7 vibrisas por lado (2); o 9 o más vibrisas por lado (3). Este carácter considera el número de vibrisas dispuestas en forma lineal sobre las almohadillas a cada lado de la hoja nasal. Los individuos de M. koepckeae, M. crenulatum keenani, M. c. longifolium, M. crenulatum "Sur", Phylloderma stenops, Lophostoma occidentalis y Tonatia saurophila exhiben 7 vibrisas; M. c. crenulatum, M. crenulatum "Amazonía", M. crenulatum "Guayanas", Phyllostomus discolor y Trachops cirrhosus exhiben 6 vibrisas. Micronycteris megalotis exhibe 5 vibrisas por lado. 
En tanto que el subgénero Mimon exhibe más de 9 vibrisas por lado. Carácter usado por primera vez en una filogenia.

Carácter 9. Número de vibrisas interramales: ausente (0); o una (1); o dos (2). La vibrisas interramales están ausentes en los individuos del subgénero anteriormente llamado "Anthorhina", el subgénero Mimon, Phyllostomus discolor y Tonatia saurophila. En Trachops cirrhosus este carácter puede estar ausente o pueden presentar una sola vibrisa. Los individuos de Phylloderma stenops y Micronycteris megalotis muestran dos vibrisas. Este carácter no fue revisado en Lophostoma occidentalis, por lo que fue codificado con "?". Carácter usado por Wetterer et al. (2000; carácter 13).

Carácter 10. Arreglo de vibrisas laterales a la hoja nasal: en dos columnas por lado (0); o una sola columna de vibrisas (1). Los estados corresponden al número de columnas de almohadillas dispuestas a los lados de la hoja nasal, sobre las cuales se insertan la vibrisas laterales. Los representantes del subgénero anteriormente llamado "Anthorhina", Phylloderma stenops, Phyllostomus discolor, Lophostoma occidentalis, Tonatia saurophila, Trachops cirrhosus y Micronycteris megalotis exhiben una sola columna de vibrisas por lado. El subgénero Mimon exhibe dos columnas de vibrisas por lado. Carácter usado por Wetterer et al. (2000; carácter 14).

Carácter 11. Largo de los pelos al contorno de la hoja nasal: ausentes (0); subiguales en todo el contorno (1); largos en la parte superior y cortos en la base (2); muy largos en la parte superior y escasos y muy cortos en la base (3). Los pelos en el contorno de la hoja nasal varían de longitud entre la mitad apical y basal del contorno del limbo; así, podemos observar pelos de tamaño similar en todo el contorno del limbo, pelos largos en la mitad apical y más cortos en la mitad basal, pelos muy largos en la mitad apical y escasos o muy cortos en la mitad basal. El estado ausente se atribuye a la ausencia de los pelos en el contorno. En M. crenulatum longifolium, M. crenulatum "Guayanas" los pelos son largos en la parte superior y cortos en la base de la hoja nasal; M. c. crenulatum, M. crenulatum "Sur" y M. crenulatum "Amazonía" exhiben pelos subiguales en todo el contorno de la hoja nasal (Figura 1a); en M. koepckeae y M. c. keenani los pelos son muy largos en la parte superior y muy cortos o escasos en la base (Figura 1b). Son ausentes en el subgénero Mimon, Phylloderma stenops, Phyllostomus discolor, Lophostoma occidentalis, Tonatia saurophila, Trachops cirrhosus y Micronycteris megalotis (Figura 1c). Carácter usado por primera vez en una filogenia.

Figura 1. Hoja nasal de: a) Mimon crenulatum crenulatum, b) M. c. keenani у с) M. bennettii.

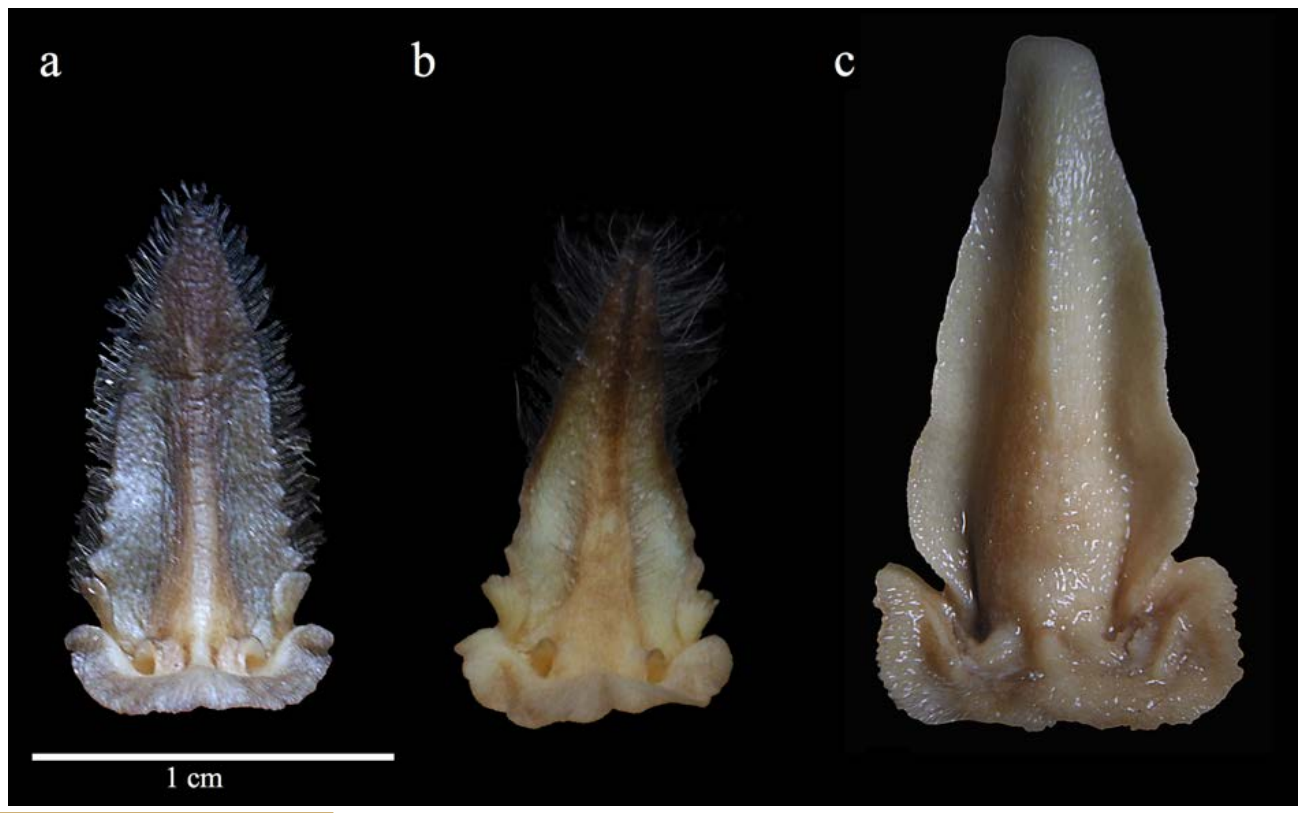


Carácter 12. Arreglo de pelos en el trago: cortos y escasos (0); o largos y densos (1). El arreglo de los pelos dispuestos en la rama principal del trago puede ser de pelos cortos y escasos o largos y densos. En Mimon crenulatum "Sur", M. c. keenani "Venezuela", M. koepckeae, el subgénero Mimon, Phylloderma stenops, Phyllostomus discolor, Trachops cirrhosus y Lophostoma occidentalis los pelos son largos y densos; M. c. crenulatum, $M$. c. longifolium, M. crenulatum "Amazonía", M. crenulatum "Guayanas", M. koepckeae, M. c. keenani "Panamá", M. c. keenani "Ecuador", M. c. keenani "Tumbes", Tonatia saurophila y Micronycteris megalotis exhiben pelos cortos y escasos en el trago. Carácter usado por primera vez en una filogenia.

Carácter 13. Color y apariencia de los parches auriculares: blanquecino e inconspicuos (0); blanco amarillento y conspicuos (1); amarillentos y conspicuos (2). Los parches auriculares corresponden a pelos de coloración contrastante ubicados en la base posterior de la oreja, estos pueden ser conspicuos o inconspicuos y de coloraciones variables. Los parches auriculares son blanco amarillento y claramente distinguibles en M. c. crenulatum, M. c. longifolium, M. crenulatum "Sur", M. crenulatum "Amazonía", M. crenulatum "Guayanas"; son inconspicuos y de color blanquecino en $M$. koepckeae, el subgénero Mimon, Phylloderma stenops, Phyllostomus discolor, Trachops cirrhosus y Micronycteris megalotis. En M. c. keenani, Lophostoma occidentalis y Tonatia saurophila los parches auriculares son brillantes y conspicuos, abarcando gran parte de la nuca. Carácter usado por primera vez en una filogenia.

Carácter 14. Parche de pelos blanquecinos entre los hombros: ausente (0); o presente (1). Los parches a la altura de los hombros, corresponden a pelos de coloración contrastante con el pelaje dorsal. Estos parches son ausente en todos los miembros del subgénero anteriormente Ilamado "Anthorhina", M. bennettii, Phyllostomus discolor, Trachops cirrhosus y Micronycteris megalotis. Están presentes en M. cozumelae, Phylloderma stenops, Lophostoma occidentalis y Tonatia saurophila. Usado por Lim (1993; carácter 2) y Wetterer et al. (2000; carácter 8).

Carácter 15. Presencia de pelos que cubren el I digito de la mano: ausente (0); o presente (1). El primer digito de la mano, libre del dactilopatagio, puede estar cubierto por densos pelos en la superficie dorsal o libre de pelos. El pulgar no está cubierto por pelos en el subgénero Mimon, Phylloderma stenops, Phyllostomus discolor, Lophostoma occidentalis y Trachops cirrhosus; en todos los representantes del subgénero anteriormente llamado "Anthorhina", Tonatia saurophila y Micronycteris megalotis el pulgar está cubierto por pelos cortos. Carácter usado por primera vez en una filogenia.

Carácter 16. Cobertura de pelos en el antebrazo: antebrazo desnudo (0); o primer tercio cubierto (1). El antebrazo es completamente desnudo, tanto en la parte dorsal como ventral, en todos los miembros del subgénero anteriormente llamado "Anthorhina", Phylloderma stenops, Phyllostomus discolor, Lophostoma occidentalis y Micronycteris megalotis (Figura 2a). Por otro lado, el primer tercio del antebrazo se encuentra cubierto dorsal y ventralmente por densos pelos en los representantes del subgénero Mimon, Tonatia saurophila y Trachops cirrhosus (Figura 2b). Carácter usado por primera vez en una filogenia.

Carácter 17. Forma del mentón: protuberante (0); o no protuberante (1). Este carácter define extensiones carnosas en el mentón para el estado protuberante, y un perfil fino para el estado no protuberante. El mentón es protuberante en M. crenulatum "Sur", 
el subgénero Mimon, Phylloderma stenops, Tonatia saurophila, Trachops cirrhosus; en contraste M. c. crenulatum, M. c. keenani, M. c. longifolium, M. crenulatum "Amazonía", M. crenulatum "Guayanas", M. koepckeae, Phyllostomus discolor, Lophostoma occidentalis y Micronycteris megalotis el mentón no sobresale del plano vertical. Carácter usado por primera vez en una filogenia.

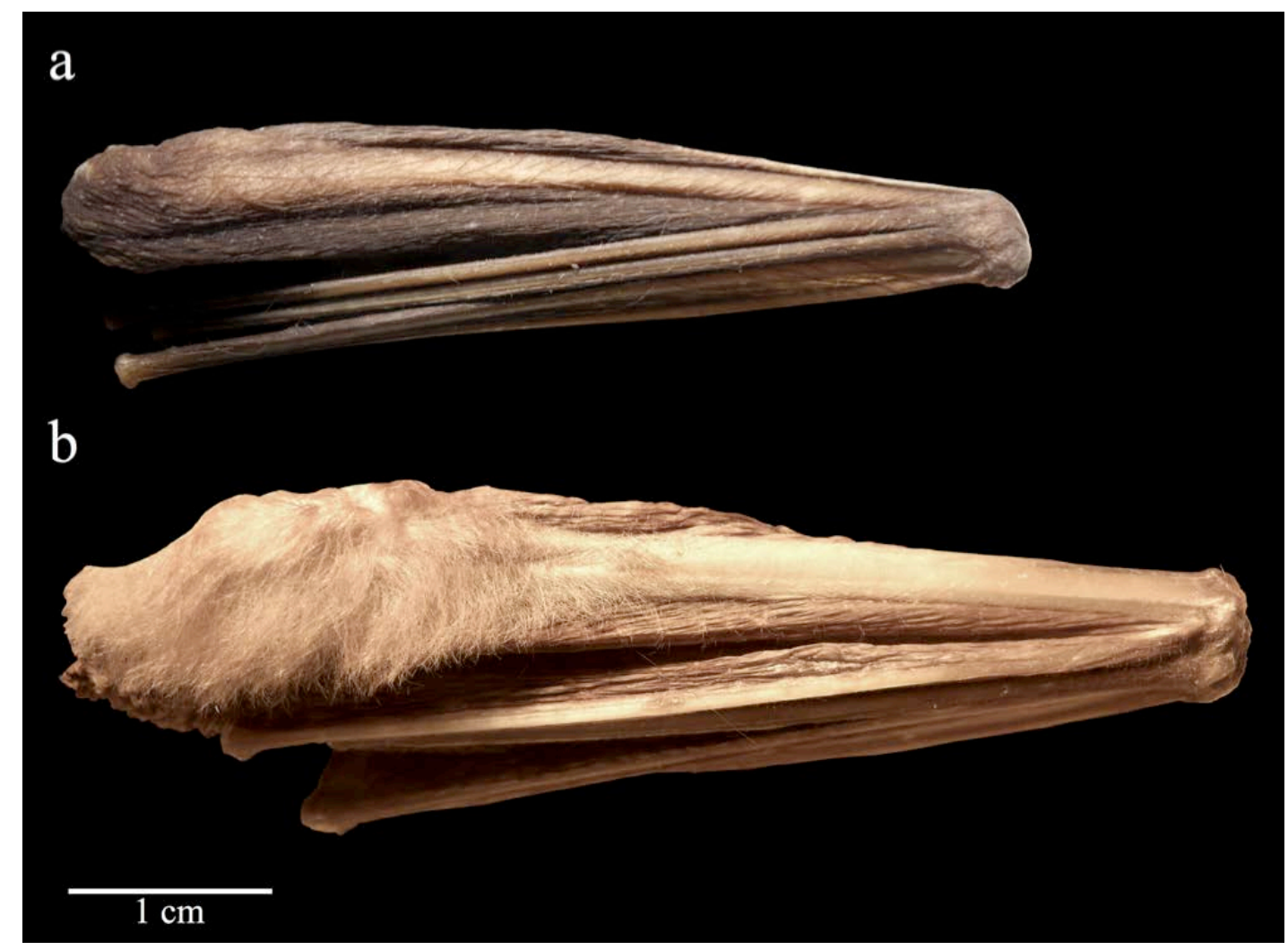

subgénero anteriormente llamado "Anthorhina" y b) subgénero Mimon.

Carácter 18. Surco central del mentón: sin surco central (0); con surco suave (1); o con surco profundo (2). El mentón puede exhibir o no un surco que lo atraviesa verticalmente, es suave cuando la profundidad es leve y no se extiende por detrás del mentón, y profundo cuando el surco es marcado y se extiende por detrás del mentón. El surco es suave en M. c. crenulatum, M. crenulatum "Amazonía", M. crenulatum "Guayanas", Tonatia saurophila y Trachops cirrhosus; es profundo en M. c. keenani, M. c. longifolium, M. crenulatum "Sur", M. koepckeae, el subgénero Mimon, Phylloderma stenops, Phyllostomus discolor y Micronycteris megalotis; y es ausente en Lophostoma occidentalis. Carácter usado por primera vez en una filogenia.

Carácter 19. Ornamentaciones de pelos en el mentón: ausente (0); o presente (1). Las ornamentaciones corresponden a pelos largos y ligeramente más gruesos y rígidos que se distribuyen radialmente sobre el mentón. Todos los representantes del subgénero anteriormente llamado "Anthorhina" y Phylloderma stenops no presentan ornamentaciones de pelos en el mentón, a diferencia del subgénero Mimon, Phyllostomus discolor, Lophostoma occidentalis, Tonatia saurophila, Trachops cirrhosus y Micronycteris megalotis que exhiben ornamentaciones. Carácter usado por primera vez en una filogenia.

Carácter 20. Disposición de papilas submentales: sin papilas centrales o un par de papilas centrales, con cinco o seis papilas dispuestas en forma oblicua a cada lado (0); o dos pares de papilas alargadas solamente (1). El carácter describe la disposición y número de papilas submentales que se disponen por debajo del labio inferior. Los miembros 
del subgénero anteriormente llamado "Anthorhina", Phyllostomus discolor, Lophostoma occidentalis y Trachops cirrhosus exhiben dos papilas centrales por lado rodeadas por una fila diagonal de cinco a seis papilas por lado, siendo el número de papilas variables por especie o población. La condición de dos papilas centrales alargadas y dos por debajo se exhiben en el subgénero Mimon y Micronycteris megalotis. En Tonatia saurophila se observa una fila diagonal adicional y en Phylloderma se aprecian las filas diagonales pero sin las papilas centrales, por lo que fueron codificadas con "?". Usado por Wetterer et al. (2000; carácter 30).

Carácter 21. Forma de las almohadillas de las vibrisas al lado de la hoja nasal: globosas (0); o ligeramente globosas (1); o aplanadas (2). Las almohadillas son estructuras carnosas ubicadas a cada lado de la hoja nasal, sobre las cuales se insertan un grupo de vibrisas, estas almohadillas pueden ser globosas cuando representan semiesferas; ligeramente globosas cuando son menos esféricas o aplanadas cuando no hay esfericidad. Las almohadillas de las vibrisas son globosas en M. c. crenulatum, M. c. longifolium, M. crenulatum "Sur", M. crenulatum "Amazonía", M. crenulatum "Guayanas", M. c. keenani "Tumbes", M. koepckeae, Tonatia saurophila y Micronycteris megalotis; son poco globosas en M. c. keenani "Panamá", "Venezuela" y "Ecuador", el subgénero Mimon, Phylloderma stenops, Phyllostomus discolor y Trachops cirrhosus. Las almohadillas son planadas en Lophostoma occidentalis. Usado por Wetterer et al. (2000; carácter 16).

Carácter 22. Longitud de la hoja nasal: menos larga que ancha (0); o longitud menor a 1.5 veces el ancho (1); o longitud menor a dos veces el ancho (2); o longitud dos veces el ancho o más (3). Es la longitud comprendida desde los nostriles hasta la punta del limbo de la hoja nasal, respecto al ancho máximo de la misma estructura. En M. c. crenulatum, M. c. longifolium, M. crenulatum "Sur", M. crenulatum "Amazonía", M. crenulatum "Guayanas" la hoja nasal sobrepasa dos veces el ancho (Figura 1a); en M. koepckeae, M. c. keenani y Micronycteris megalotis la longitud es menor a dos veces el ancho de la hoja nasal (Figura 1b). La hoja nasal de Tonatia saurophila es menos larga que ancha. El subgénero Mimon, Phylloderma stenops, Phyllostomus discolor, Trachops cirrhosus y Lophostoma occidentalis la hoja nasal es más larga que ancha pero no excede 1.5 veces el ancho (Figura 1c). Usado por Owen (1987; carácter 2) quien mide la longitud de la hoja nasal respecto al ancho de la misma. Wetterer et al. (2000; carácter 19), definieron dos estados: hoja nasal más grande que dos veces la altura de la herradura, u hoja nasal truncada igual o menor a la longitud de la herradura.

Carácter 23. Forma de la hoja nasal: lanceolada (0); o acorazonada (1). La forma de la hoja nasal es lanceolada cuando el limbo es angosto y largo como una navaja; es acorazonada cuando es ensanchado en la parte media. La hoja nasal es lanceolada en todos los representantes del subgénero anteriormente llamado "Anthorhina" y Micronycteris megalotis (Figura 1a y b); en contraste es acorazonada en el subgénero Mimon, Phylloderma stenops, Phyllostomus discolor, Lophostoma occidentalis, Tonatia saurophila y Trachops cirrhosus (Figura 1c). Carácter usado por primera vez en una filogenia.

Carácter 24. Crenulaciones al borde la hoja nasal: ausentes (0); o poco marcadas en todo el borde pero distinguibles (1); o marcadas sólo en la mitad basal de la hoja nasal (2); o marcadas en todo el borde la hoja nasal (3). El borde del limbo de la hoja nasal puede presentar o no crenulaciones en el borde; que corresponden a plegamientos de la piel de profundidad y extensión variable. La hoja nasal presenta crenulaciones desde la base hasta la parte media de la hoja nasal en M. c. crenulatum, M. c. longifolium, M. crenulatum 
"Amazonía", M. crenulatum"Guayanas" y M. koepckeae. Mimon c. keenani y M. crenulatum"Sur" exhiben crenulaciones muy marcadas en todo el borde (Figura 1a y b). Las crenulaciones son poco marcadas en Tonatia saurophila y Trachops cirrhosus. Son ausentes en el subgénero Mimon, Phylloderma stenops, Phyllostomus discolor, Lophostoma occidentalis y Micronycteris megalotis (Figura 1c). Carácter usado por primera vez en una filogenia.

Carácter 25. Pigmentación en la hoja nasal: ausente (0); o parcial (1); o completa (2). Corresponde a la proporción de pigmento oscuro en el limbo de la hoja nasal. La pigmentación es completa en Phyllostomus discolor, Lophostoma occidentalis, Tonatia saurophila y Micronycteris megalotis; es parcial con patrones diversos en M. c. crenulatum, $M$. c. longifolium, M. crenulatum "Sur", M. crenulatum "Amazonía", M. crenulatum "Guayanas", M. c. keenani"Ecuador", M. c. keenani"Tumbes"yM. koepckeae. La hoja no se encuentra pigmentada en M. c. keenani "Panamá", M. c. keenani "Venezuela", el subgénero Mimon y Trachops cirrhosus. Wetterer et al. (2000; carácter 18), usan este carácter, establecen características de la totalidad de la coloración tomando los estados parcialmente bicoloreado, unicoloreado, o bicoloreado bien definido.

Carácter 26. Forma del borde inferior de la herradura: borde delgado a manera de una solapa de piel libre (0); o borde engrosado sin márgenes libres (1). El borde anterior de la herradura de todos los especímenes evaluados es continuo, sin embargo, éste puede extenderse hacia el labio a manera de una solapa. El borde es engrosado sin dejar piel libre en el subgénero Mimon, Phylloderma stenops, Lophostoma occidentalis, Tonatia saurophila, Trachops cirrhosus y Micronycteris megalotis. El borde anterior de la herradura deja un borde libre de piel a manera de solapa en todos los representantes del subgénero anteriormente llamado "Anthorhina" y Phyllostomus discolor. Usado por Wetterer et al. (2000; carácter 25) y Velazco (2005; carácter 9).

Carácter 27. Forma de la rama principal del trago: aguda (0); o redondeada (1). La rama principal del trago es aguda en $M$. crenulatum "Sur", M. crenulatum "Amazonia", $M$. koepckeae, el subgénero Mimon, Phylloderma stenops, Lophostoma occidentalis, Trachops cirrhosus y Micronycteris megalotis (Figura 3c). En M. crenulatum keenani, M. c. crenulatum, $M$. c. longifolium, M. crenulatum "Guayanas", Phyllostomus discolor y Tonatia saurophila la rama principal del trago es redondeada (Figura $3 a$ y b). Carácter usado por primera vez en una filogenia.

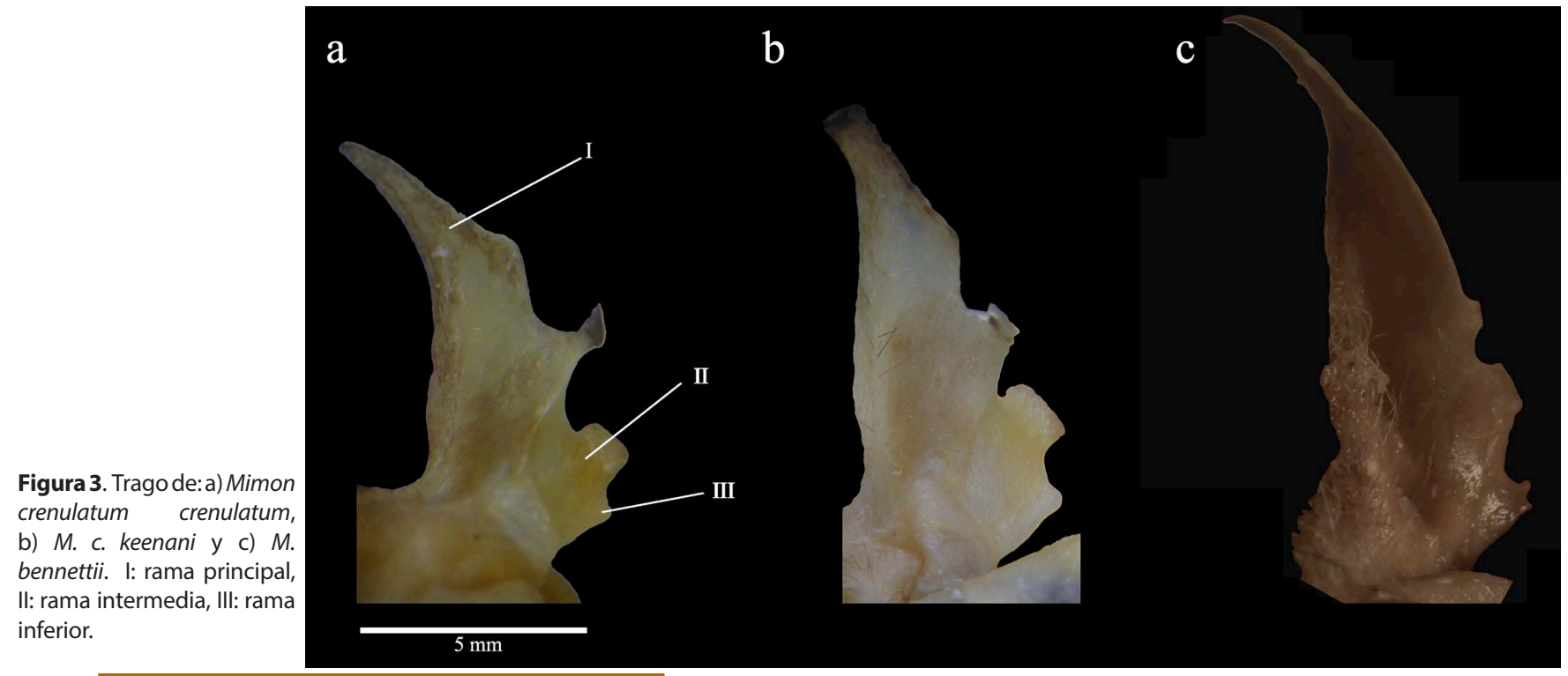


Carácter 28. Forma de la rama intermedia del trago: plana y delgada (0); o plana y engrosada (1); o globosa y engrosada (2). En plana y engrosada en M. c. crenulatum, $M$. crenulatum "Amazonía", M. crenulatum "Guayanas", Phylloderma stenops, Tonatia saurophila y Trachops cirrhosus (Figura 3a); es globosa y engrosada en M. koepckeae, M. c. keenani, M. C. longifolium, M. crenulatum "Sur" y Phyllostomus discolor (Figura 3b); es plana y delgada en el subgénero Mimon, Lophostoma occidentalis y Micronycteris megalotis (Figura 3c). Carácter usado por primera vez en una filogenia.

Carácter 29. Forma de la rama interior del trago: corta (0); o pronunciada (1); o muy pronunciada (2). La rama inferior del trago es corta en M. crenulatum "Sur", el subgénero Mimon y Micronycteris megalotis (Figura 3c); es muy pronunciada en M. c. crenulatum, M. c. longifolium, M. crenulatum "Amazonía", M. crenulatum "Guayanas", M. koepckeae, Phyllostomus discolor, Lophostoma occidentalis y Tonatia saurophila (Figura 3a). La rama inferior del trago es pronunciada en M. c. keenani, Phylloderma stenops y Trachops cirrhosus (Figura 3b). Carácter usado por primera vez en una filogenia.

Carácter 30. Tamaño de la oreja: corta menor a $22 \mathrm{~mm}$ (0); o mediana, de 23 a $26 \mathrm{~mm}$ (1); o larga, mayor a $30 \mathrm{~mm}$ (2). La longitud de la oreja, medida desde la base hasta la punta, es corta en M. c. crenulatum, M. c. longifolium, M. crenulatum "Amazonía", M. crenulatum "Guayanas", Phylloderma stenops, Phyllostomus discolor y Micronycteris megalotis (Figura 4a); es mediana en M. c. keenani, M. crenulatum "Sur" y M. koepckeae (Figura 4b). En el subgénero Mimon, Lophostoma occidentalis, Tonatia saurophila y Trachops cirrhosus, la longitud de la oreja sobrepasa los $30 \mathrm{~mm}$ (Figura 4c). Carácter usado por primera vez en una filogenia.

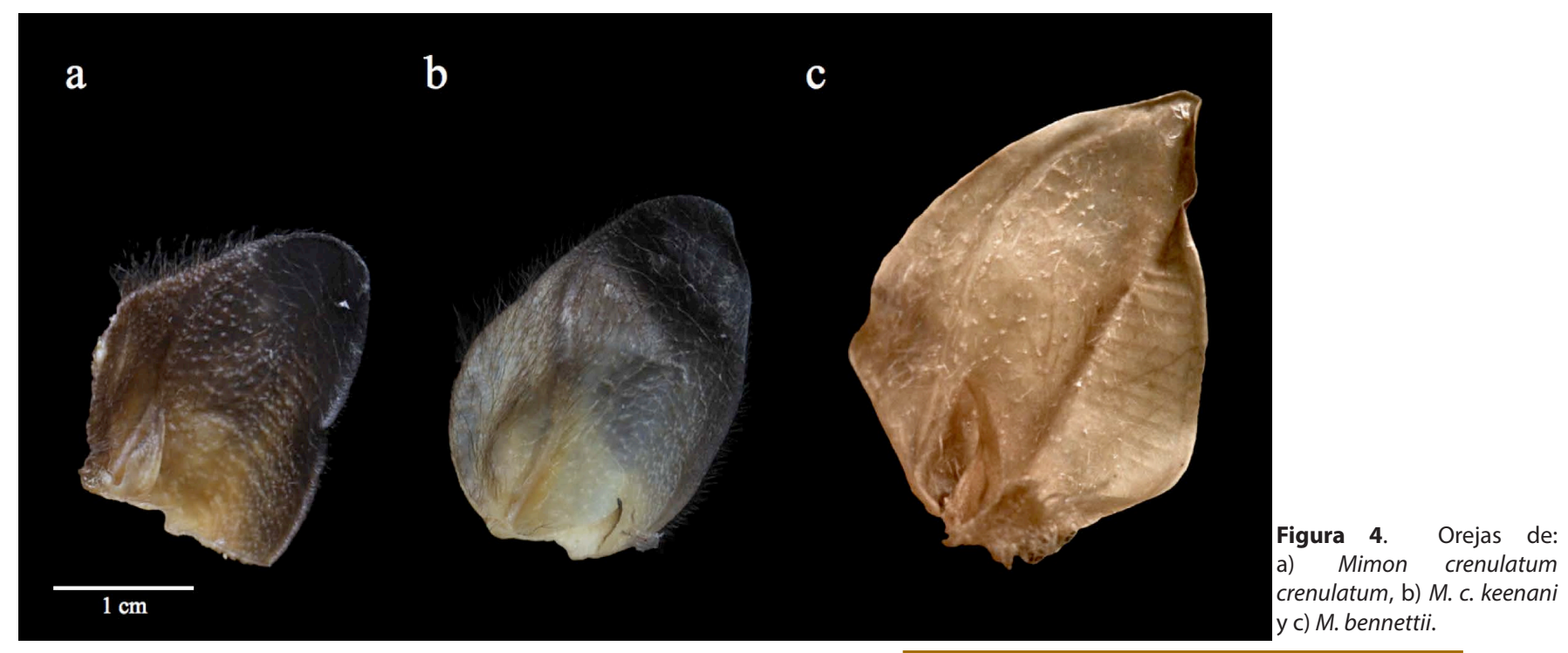

Carácter 31. Forma de la oreja: lanceolada de puntas paralelas sin proyección (0); - lanceolada de puntas divergentes con proyección hacia el exterior (1). Las orejas son lanceolada de puntas paralelas en todos los representantes del subgénero anteriormente llamado "Anthorhina", Phylloderma stenops, Lophostoma occidentalis, Tonatia saurophila, Trachops cirrhosus y Micronycteris megalotis (Figura 4a y b). En contraste, los representantes del subgénero Mimon y Phyllostomus discolor tienen orejas lanceoladas de puntas divergentes con proyecciones hacia el exterior (Figura 4c). Carácter usado por primera vez en una filogenia. 
Carácter 32. Pliegues paralelos de la oreja: ligeramente marcados, pero distinguibles (0); o muy bien definidos (1). La superficie interna del lóbulo externo de la oreja presenta plegamientos horizontales que varían en profundidad, siendo ligeramente marcados cuando son poco elevados o muy bien definidos cuando los pliegues son altos. En los individuos de todas las poblaciones de M. crenulatum keenani, M. koepckeae y en Phyllostomus discolor los pliegues son distinguibles y se encuentran ligeramente marcados. Los pliegues se aprecian muy bien marcados en M. c. crenulatum, M. c. longifolium, M. crenulatum "Sur", M. crenulatum "Amazonía", M. crenulatum "Guayanas", el subgénero Mimon, Phylloderma stenops, Lophostoma occidentalis, Tonatia saurophila, Trachops cirrhosus y Micronycteris megalotis. Este carácter fue usado por Velazco (2005; carácter 10).

Carácter 33. Pigmentación de la oreja: parcialmente pigmentada (0); o completamente pigmentada (1). Corresponde a la proporción de la oreja con pigmentación oscura. Es parcialmente pigmentada cuando mitad superior presenta coloración oscura y la mitad inferior, incluido el trago, no. Es completamente pigmentada cuando toda la oreja presenta coloración oscura, incluyendo al trago. La oreja es parcialmente pigmentada en todos los representantes del subgénero anteriormente Ilamado "Anthorhina" y Trachops cirrhosus (Figura 4 a y b). La pigmentación es completa en el subgénero Mimon, Phylloderma stenops, Phyllostomus discolor, Lophostoma occidentalis, Tonatia saurophila y Micronycteris megalotis (Figura 4c). Carácter usado por primera vez en una filogenia.

Carácter 34. Grosor de la oreja: oreja carnosa (0); o oreja translúcida (1). Corresponde a la textura de la oreja en cuando a grosor. Es carnosa cuando es lo suficientemente gruesa para no ver a través de ella en luz natural. Es translúcida cuando es lo suficientemente delgada que permite observar a través de ella. La pina es carnosa en todos los representantes del subgénero anteriormente llamado "Anthorhina", Phylloderma stenops, Phyllostomus discolor, Tonatia saurophila, Trachops cirrhosus y Micronycteris megalotis (Figura $4 a$ y b). En el subgénero Mimon y Lophostoma occidentalis la oreja es translúcida (Figura 4c). Carácter usado por primera vez en una filogenia.

Carácter 35. Forma del borde de la oreja: engrosado y con crenulaciones (0); o delgado y liso (1). Los bordes de la oreja se encuentran engrosados y con crenulaciones en M. c. crenulatum, M. c. longifolium, M. crenulatum "Amazonía", M. crenulatum "Guayanas", Phylloderma stenops y Phyllostomus discolor (Figura 4a); en tanto que en M. koepckeae, M. c. keenani M. crenulatum "Sur", el subgénero Mimon, Lophostoma occidentalis, Tonatia saurophila, Trachops cirrhosus y Micronycteris megalotis los bordes son delgados y lisos (Figura 4b y c). Carácter usado por primera vez en una filogenia.

Carácter 36. Protuberancias en el lóbulo interno de la oreja: conglomeradas y desarrolladas (0); o esparcidas y poco desarrolladas (1). Las protuberancias en la superficie interna son conglomeradas y desarrolladas en $M$. c. crenulatum, M. c. longifolium, $M$. crenulatum "Amazonía", M. crenulatum "Guayanas", Phylloderma stenops, Phyllostomus discolor, Lophostoma occidentalis, Trachops cirrhosus y Micronycteris megalotis (Figura 4a). Son esparcidas y poco desarrolladas pero distinguibles en M. koepckeae, M. c. keenani, $M$. crenulatum "Sur", el subgénero Mimon y Tonatia saurophila (Figura 4b y c). Carácter usado por primera vez en una filogenia.

Carácter 37. Desarrollo del lóbulo interno de la oreja: desarrollado (0); o poco desarrollado (1). El lóbulo interno de la oreja es claramente desarrollado en $M$. $c$. crenulatum, M. c. longifolium, M. crenulatum "Sur", M. crenulatum "Amazonía", M. crenulatum 
"Guayanas", Lophostoma occidentalis, Tonatia saurophila, Trachops cirrhosus y Micronycteris megalotis (Figura 4a). Es poco desarrollado en M. koepckeae, M. c. keenani, el subgénero Mimon, Phylloderma stenops y Phyllostomus discolor (Figura 4b y c). Carácter usado por primera vez en una filogenia.

Carácter 38. Pliegue en la base exterior de la oreja: poco profundo (0); o muy profundo (1). La base exterior donde la oreja se inserta a la cabeza presenta un plegamiento de piel con diferentes grados de profundidad hacia el interior. El pliegue es poco profundo en todos los representantes del subgénero anteriormente llamado "Anthorhina", Phylloderma stenops, Phyllostomus discolor, Tonatia saurophila, Trachops cirrhosus y Micronycteris megalotis (Figura 5a); en el subgénero Mimon y Lophostoma occidentalis el pliegue es bastante profundo y definido (Figura 5b). Carácter usado por primera vez en una filogenia.

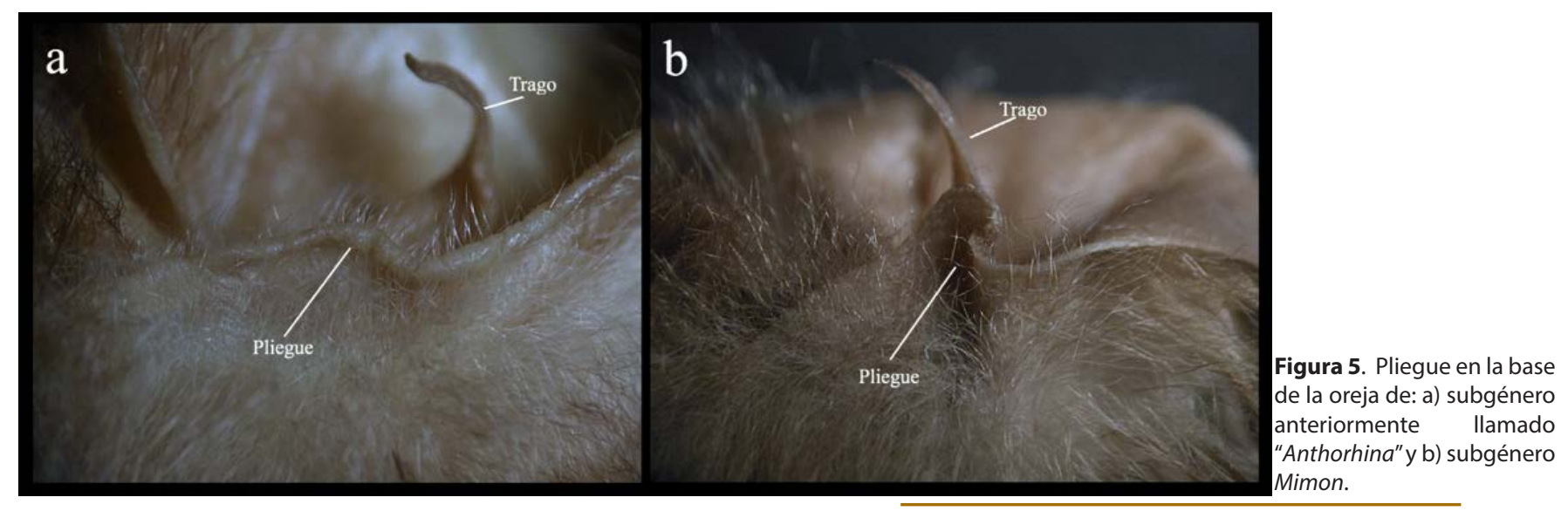

Carácter 39. Presencia de la glándula gular: ausente (0); o presente (1). Corresponde a una estructura para exudación odorífera presente en individuos adultos (machos y hembras), ubicada en la parte central de la garganta. La glándula gular está presente en todos los representantes del subgénero anteriormente llamado "Anthorhina", en Phylloderma stenops, Phyllostomus discolor, Trachops cirrhosus y Micronycteris megalotis. Es ausente en el subgénero Mimon, Lophostoma occidentalis y Tonatia saurophila. Carácter usado por primera vez en una filogenia.

Carácter 40. Pigmentación en la punta de la alas: despigmentadas (0); o pigmentadas (1). Corresponde a la proporción del plagiopatagio sin pigmentación. Las puntas de las alas son completamente pigmentadas en M. c. crenulatum, M. c. longifolium, M. crenulatum "Sur", M. crenulatum "Amazonía", M. crenulatum "Guayanas", M. koepckeae, Phyllostomus discolor, Lophostoma occidentalis y Micronycteris megalotis. Las puntas se encuentra despigmentadas en las alas de M. c. keenani, el subgénero Mimon, Phylloderma stenops, Tonatia saurophila y Trachops cirrhosus. Carácter usado por primera vez en una filogenia.

Carácter 41. Pigmentación de la planta de la pata: ausente (0); o presente (1). La planta de la pata es pigmentada en todos los representantes del subgénero anteriormente llamado "Anthorhina", Phyllostomus discolor, Lophostoma occidentalis, Tonatia saurophila y Micronycteris megalotis (Figura 6a). En el caso del subgénero Mimon, Phylloderma stenops y Trachops cirrhosus la patas no son pigmentadas (Figura 6b). Carácter usado por primera vez en una filogenia.

Carácter 42. Arreglo de pelos en el dorso de la pata: esparcidos y cortos (0); o ligeramente densos y largos (1); o densos y largos (2). En M. crenulatum longifolium, M. crenulatum "Sur", 
M. koepckeae y M. c. keenani los pelos del dorso de la pata son densos y largos (Figura 6a); en tanto que en M. c. crenulatum, M. crenulatum "Amazonía", M. crenulatum "Guayanas", Phylloderma stenops, Tonatia saurophila, Trachops cirrhosus y Micronycteris megalotis los pelos son ligeramente densos y largos; en el subgénero Mimon, Phyllostomus discolor y Lophostoma occidentalis los pelos son esparcidos y cortos (Figura 6b). Usado por Velazco (2005; carácter 15).

Figura 6. Punto deinserción del plagiopatagio del: a) subgénero anteriormente llamado "Anthorhina" y b) subgénero Mimon.
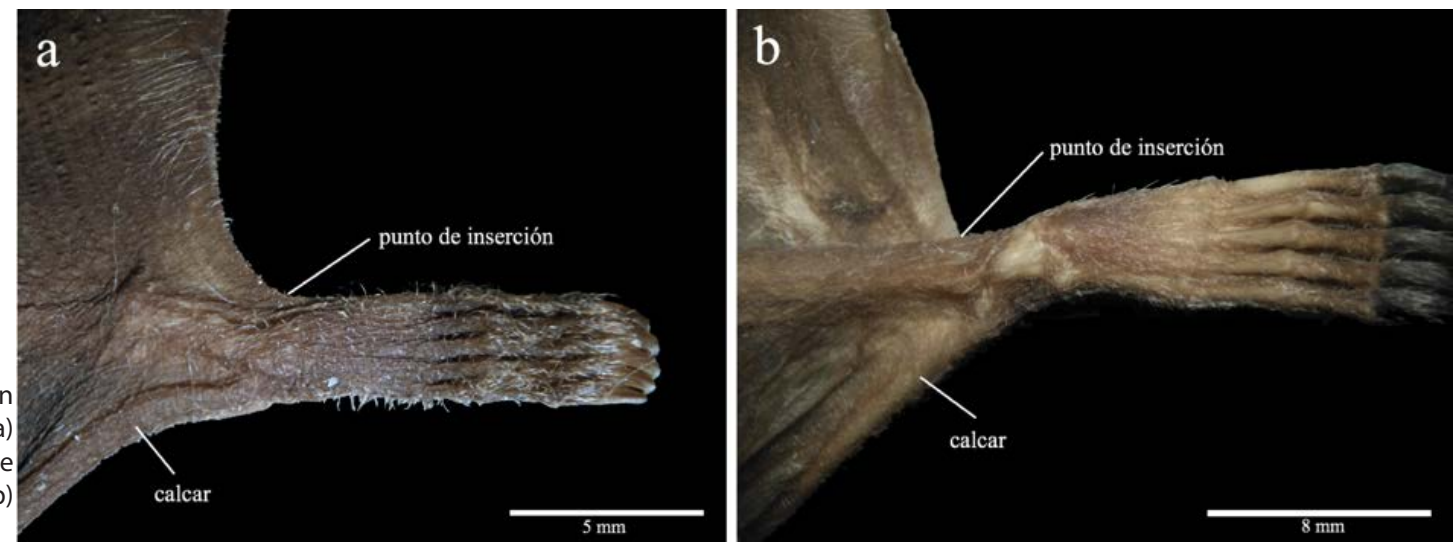

Carácter 43. Presencia de peine de pelos en el uropatagio: ausente (0); o con pelos esparcidos y cortos (1); o exhibe peine bien definido de pelos largos (2). El peine de pelos es ausente en las poblaciones de M. crenulatum keenani, el subgénero Mimon, Phylloderma stenops, Phyllostomus discolor, Lophostoma occidentalis, Tonatia saurophila, Trachops cirrhosus y Micronycteris megalotis; M. c. crenulatum, M. c. longifolium, M. crenulatum "Amazonía", M. crenulatum "Guayanas" y M. koepckeae presentan pelos esparcidos y cortos. En M. crenulatum "Sur" el peine de pelos está compuesto por pelos largos regularmente dispuestos. Usado por Lim (1993; carácter 13), Wetterer et al. (2000; carácter 10) y Velazco (2005; carácter 17).

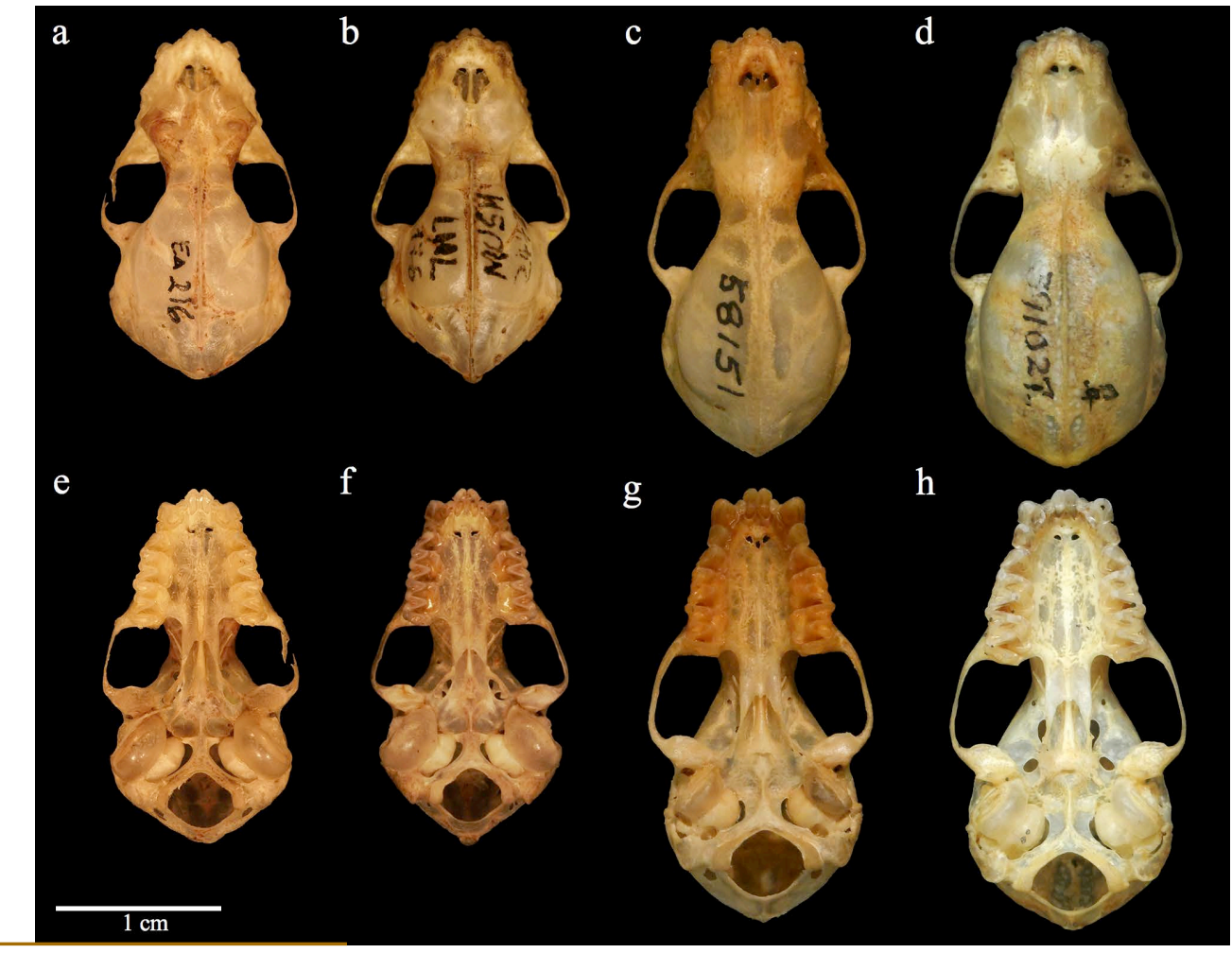

Figura 7. Vista dorsal y ventral de los cráneos de Mimon kopeckeae (a y e), M. crenulatum (b y f), M. cozumelae (c y g) y $M$. bennettii (d y h). 
Craneodentales. Carácter 44. Forma de los nostriles: en forma de "V" $(0)$; o en forma de " $U$ " (1); o en forma de omega con bordes rectos hasta encía (2); o sin depresión, es decir, borde anterior de los nasales recto (3). El nostril corresponde a los bordes anteriores de los nasales, el cual varía en forma. En M. koepckeae tienen forma de "V" (Figura 7a). Mimon crenulatum keenani, M. c. crenulatum, M. c. longifolium, M. crenulatum "Sur", M. crenulatum "Amazonía", M. crenulatum "Guayanas", Tonatia saurophila, Trachops cirrhosus y Micronycteris megalotis tienen forma de omega (Figura 7b). Son rectos en el subgénero Mimon, Phylloderma stenops y Phyllostomus discolor (Figura 7c y d). En Lophostoma occidentalis tienen forma de "U". Carácter usado por primera vez en una filogenia.

Carácter 45. Forma del perfil del rostro: plano (0); o ligeramente curvado (1); o muy curvado (2). La forma de la parte dorsal más anterior del rostro, en vista lateral, da al perfil una forma aplanada cuando no presenta elevación; o curvada dependiendo del grado de elevación de la parte anterior. En M. c. crenulatum, M. c. longifolium, M. crenulatum "Sur", M. crenulatum "Amazonía", M. crenulatum "Guayanas", M. koepckeae y Trachops cirrhosus el perfil es ligeramente curvado (Figura 8 a y b). En todas las poblaciones de M. c. keenani el perfil es muy curvado, debido a que el borde anterior es muy elevado. En el subgénero Mimon, Phylloderma stenops, Phyllostomus discolor, Lophostoma occidentalis, Tonatia saurophila y Micronycteris megalotis el perfil es plano (Figura $8 \mathrm{c}$ y d). Carácter usado por primera vez en una filogenia.

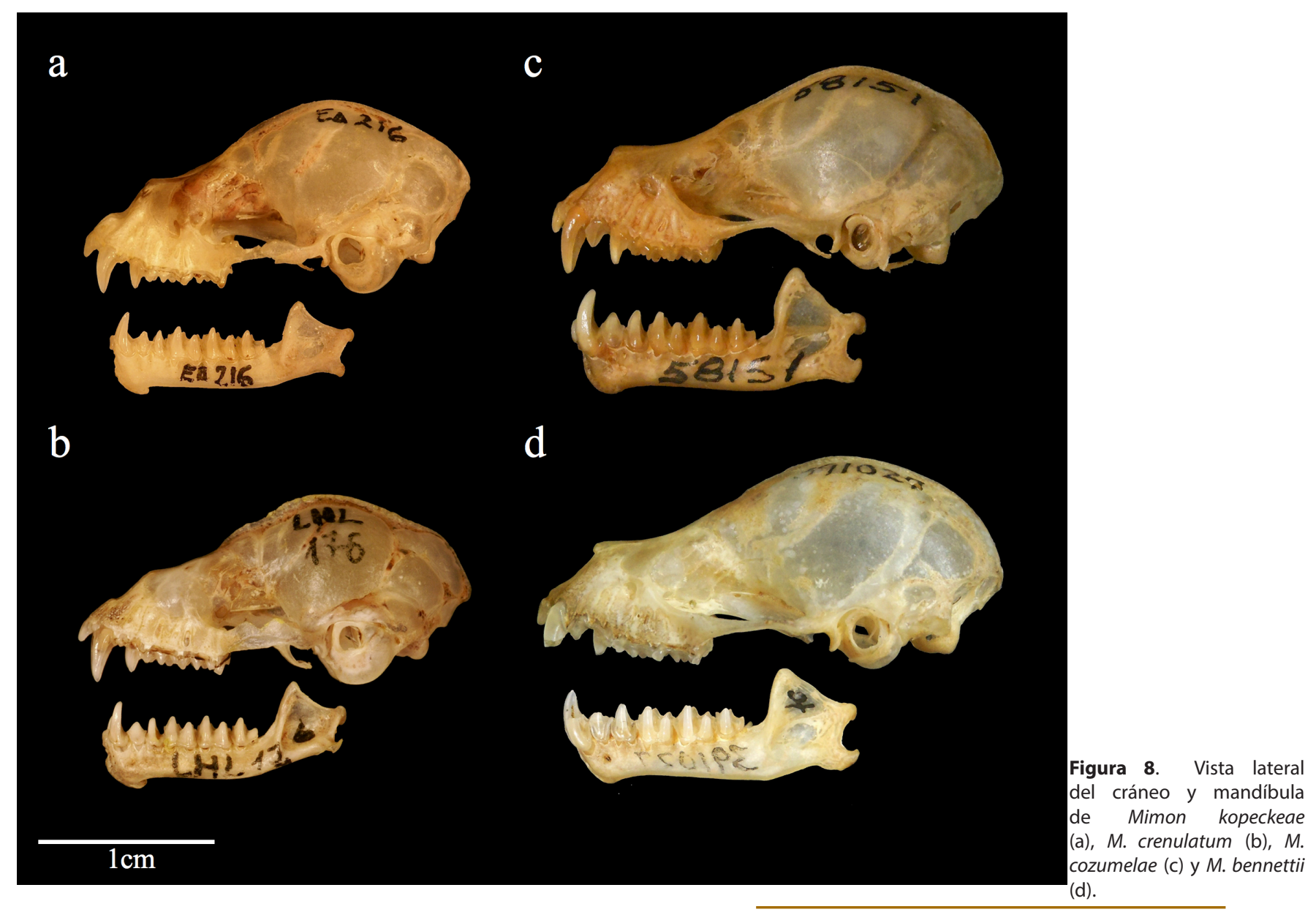


Carácter 46. Longitud de los nasales: cortos (0); o largos (1). Los nasales son cortos cuando son menores a la mitad de la longitud del rostro y largo cuando son mayores a la mitad de la longitud rostral. Son cortos en todos los miembros del subgénero anteriormente llamado "Anthorhina", así como en Phylloderma stenops, Tonatia saurophila y Trachops cirrhosus (Figura 7a y b); en el subgénero Mimon, Phyllostomus discolor, Lophostoma occidentalis y Micronycteris megalotis los nasales son largos (Figura 7c y d). Carácter usado por primera vez en una filogenia.

Carácter 47. Disposición de las crestas de los incisivos: crestas casi paralelas (0); o crestas diagonales no convergentes en la base (1); o crestas diagonales convergentes en la base (2). Dorsalmente el cráneo exhibe crestas en la encía donde se insertan los incisivos superiores. Estas crestas varían en disposición, siendo casi paralelas en M. c. crenulatum, M. c. longifolium, $M$. crenulatum "Sur", M. crenulatum "Amazonía", M. crenulatum "Guayanas", M. c. keenani y Trachops cirrhosus (Figura 7a y b). En M. koepckeae y Tonatia saurophila las crestas son convergentes en la base. En el subgénero Mimon, Phylloderma stenops, Phyllostomus discolor, Lophostoma occidentalis y Micronycteris megalotis las crestas son diagonales pero no convergentes en la base (Figura 7c y d). Carácter usado por primera vez en una filogenia.

Carácter 48. Depresión media rostral: ausente (0); o ligeramente profunda (1); o profunda (2). La depresión media rostral corresponde a una concavidad distinguible en el centro de la frente. La depresión media rostral es notablemente profunda en M. c. crenulatum, M. c. longifolium, M. crenulatum "Sur", M. crenulatum "Amazonía" y M. crenulatum "Guayanas". Es ligeramente profunda en todas las poblaciones de M. c. keenani. La depresión media rostral no está presente en el subgénero Mimon, Phylloderma stenops, Phyllostomus discolor, Lophostoma occidentalis, Tonatia saurophila, Trachops cirrhosus y Micronycteris megalotis. Carácter usado por primera vez en una filogenia.

Carácter 49. Forma de la raíz maxilar del cigoma: plana (0); o ligeramente inflamada (1); o muy inflamada (2). Las raíces del cigoma son planas en el subgénero Mimon, Phyllostomus discolor, Lophostoma occidentalis y Tonatia saurophilas. En M. c. crenulatum, M. c. longifolium, M. crenulatum "Sur", M. crenulatum "Amazonía", M. crenulatum "Guayanas", Trachops cirrhosus y Micronycteris megalotis las raíces son ligeramente inflamadas. En M. koepckeae, M. c. keenani y Phylloderma stenops las raíces son muy inflamadas. Carácter usado por primera vez en una filogenia.

Carácter 50. Perfil de la caja craneana: inflamada anteriormente (0); o no inflamada anteriormente (1). En vista lateral, la caja craneana exhibe una inflamación en la zona frontal de M. crenulatum"Sur", Phylloderma stenops, Phyllostomus discolor, Tonatia saurophila y Micronycteris megalotis; por otra parte M. c. crenulatum, M. c. longifolium, M. crenulatum "Amazonía", M. crenulatum "Guayanas", M. koepckeae, M. c. keenani, el subgénero Mimon, Lophostoma occidentalis y Trachops cirrhosus exhiben la frente no inflamada. Carácter usado por primera vez en una filogenia.

Carácter 51. Forma del borde posterior de la caja craneana: redondeada (0); o con vértice por la presencia de proceso poco desarrollado (1); o vértice afilado por presencia de proceso muy desarrollado (2). El borde posterior de la caja craneana presenta una proyección desarrollada en M. crenulatum "Sur", Lophostoma occidentalis, Tonatia saurophila y Trachops cirrhosus; esta proyección es menos protuberante pero distinguible en M. c. crenulatum, M. c. longifolium, M. crenulatum "Amazonía", M. crenulatum "Guayanas", M. c. keenani, Phyllostomus discolor; en M. koepckeae, el subgénero Mimon, Phylloderma stenops y Micronycteris megalotis el borde posterior es redondeado. Carácter usado por primera vez en una filogenia. 
Carácter 52. Desarrollo de la cresta sagital: poco desarrollada (0); o medianamente desarrollada (1); o muy desarrollada (2). La cresta sagital es una proyección dorsal vertical del cráneo, que varía en altura y extensión. Es poco desarrollada en M. crenulatum keenani "Tumbes", M. koepckeae, el subgénero Mimon, Phylloderma stenops, Phyllostomus discolor y Micronycteris megalotis (Figura 8a, c y d); medianamente desarrollada en M. c. longifolium, $M$. crenulatum "Sur", Tonatia saurophila y Trachops cirrhosus (Figura 8b); y muy desarrollada en M. crenulatum "Amazonía" y Lophostoma occidentalis. No se analizó el carácter en los demás taxones por lo que fue codificado como"?". Carácter usado por primera vez en una filogenia.

Carácter 53. Longitud relativa de la caja craneana: de longitud igual que el rostro (0); más grande que el rostro (1); o dos veces la longitud del rostro (2). La caja craneana es de igual longitud que el rostro en M. c. crenulatum, M. c. longifolium, M. crenulatum "Amazonía", M. crenulatum "Guayanas" y M. koepckeae. Es más grande que el rostro en M. c. keenani, M. crenulatum "Sur", Lophostoma occidentalis, Tonatia saurophila y Trachops cirrhosus. Es dos veces o más la longitud del rostro en el subgénero Mimon, Phylloderma stenops, Phyllostomus discolor y Micronycteris megalotis. Usado por Simmons y Conway (2001: Carácter 9), comparan el largo del rostro respecto al largo total del cráneo.

Carácter 54. Longitud del cráneo: menor a $22.5 \mathrm{~mm}$ (0); o mayor a $25.0 \mathrm{~mm}$ (1). Es la longitud medida desde la inserción de los incisivos hasta del borde posterior de la caja craneana. La longitud es menor a $22.5 \mathrm{~mm}$ en todos los integrantes del subgénero anteriormente llamado "Anthorhina" y Micronycteris megalotis. Es mayor a $25.0 \mathrm{~mm}$ en el subgénero Mimon, Phylloderma stenops, Phyllostomus discolor, Lophostoma occidentalis, Tonatia saurophila y Trachops cirrhosus. Carácter usado por primera vez en una filogenia.

Carácter 55. Forma del jugal: cilíndrico y angosto (0); o aplanado, ancho y frágil (1); o aplanado, ancho y robusto (2). El jugal es cilíndrico y angosto en el subgénero Mimon, Phylloderma stenops y Lophostoma occidentalis. Es aplanado, ancho y frágil en M. c. crenulatum, M. c. longifolium, M. crenulatum "Sur", M. crenulatum "Amazonía", M. koepckeae y Phyllostomus discolor. Es aplanado, ancho y robusto en M. c. keenani, M. crenulatum "Guayanas", Tonatia saurophila, Trachops cirrhosus y Micronycteris megalotis. Carácter usado por primera vez en una filogenia.

Carácter 56. Amplitud de la constricción postorbital: más ancha que el espacio entre los caninos (0); o más angosta que el espacio entre los caninos (1). La constricción postorbital es más ancha que el espacio entre lo caninos en Phylloderma stenops, Phyllostomus discolor, Tonatia saurophila y Micronycteris megalotis. Es más angosta que el espacio entre los caninos en el subgénero anteriormente Ilamado "Anthorhina", el subgénero Mimon, Lophostoma occidentalis y Trachops cirrhosus. Carácter usado por primera vez en una filogenia.

Carácter 57. Amplitud relativa del paladar: igual o más ancho que la región postorbital (0); o menos ancho que la región postorbital (1). El paladar es igual o más ancho que la región postorbital en M. koepckeae, Phylloderma stenops, Phyllostomus discolor, Lophostoma occidentalis, Tonatia saurophila y Trachops cirrhosus. Es menos ancho en M. c. crenulatum, M. c. longifolium, M. c. keenani, M. crenulatum "Sur", M. crenulatum "Amazonía", M. crenulatum "Guayanas", el subgénero Mimon y Micronycteris megalotis. Carácter usado por primera vez en una filogenia.

Carácter 58. Forma del piso del paladar: cóncavo (0); o ligeramente cóncavo (1); o plano (2). El piso del paladar es ligeramente cóncavo en M. c. crenulatum, M. c. longifolium, M. crenulatum "Sur", M. crenulatum "Amazonía", M. crenulatum "Guayanas", el subgénero 
Mimon, Lophostoma occidentalis, Phyllostomus discolor, Trachops cirrhosus y Micronycteris megalotis. Es cóncavo en M. koepckeae, M. c. keenani y Tonatia saurophila. Es plano en Phylloderma stenops. Usado por Pacheco y Patterson (1991; carácter 13).

Carácter 59. Ubicación de la premaxila en el paladar: al mismo nivel de la maxila (0); o por debajo de la maxila (1). En vista ventral, el piso del paladar en la premaxila puede estar por debajo o no del piso de la maxila. Todos los miembros del subgénero anteriormente llamado "Anthorhina" presentan la premaxila por debajo del nivel de la maxila al igual que en Phylloderma stenops, Tonatia saurophila y Micronycteris megalotis; la maxila y la premaxila se encuentran en el mismo plano en el subgénero Mimon, Phyllostomus discolor, Lophostoma occidentalis y Trachops cirrhosus. Carácter usado por primera vez en una filogenia.

Carácter 60. Forma del borde posterior de la premaxila: exhibe una muesca extendida hacia la maxila en forma de " $\mathrm{V}$ " (0); o exhibe una muesca corta y redondeada dirigida hacia la maxila (1); o exhibe borde sin muesca (2). Mimon crenulatum "Amazonía", M. crenulatum "Guayanas", M. koepckeae y Micronycteris megalotis presentan una muesca en forma de V. Mimon c. crenulatum, M. c. Iongifolium, M. c. keenani, M. crenulatum "Sur" y Tonatia saurophila exhiben muesca corta y redondeada. El subgénero Mimon, Phylloderma stenops, Phyllostomus discolor, Lophostoma occidentalis y Trachops cirrhosus no exhiben ningún tipo de muesca. Carácter usado por primera vez en una filogenia.

Carácter 61. Amplitud del tabique medio del proceso palatino en la premaxila: angosto (0); o ancho (1). El tabique medio del proceso palatino - mfpp (Giannini y Simmons 2007) corresponde a la estructura ósea ubicada entre los forámenes incisivos. En M. c. crenulatum, M. crenulatum "Amazonía", M. crenulatum "Guayanas", M. bennettii, Phylloderma stenops, Phyllostomus discolor, Lophostoma occidentalis, Trachops cirrhosus y Micronycteris megalotis el mlpp es angosto. En M. c. keenani, M. c. longifolium, M. c. "Sur", M. koepckeae, M. cozumelae y Tonatia saurophila el mfpp es ancho. Owen (1987: carácter 8) se refiere a esta estructura como el septo que separa los forámenes incisivos, los estados se refieren a la presencia y al número de tabiques de esta estructura.

Carácter 62. Posición del foramen accesorio medio: ubicado en la parte media anterior de los forámenes incisivos (0); o en la parte media o posterior de los forámenes incisivos (1); o ausente (2). El foramen accesorio medio - afo (Giannini y Simmons 2007) es un orificio ubicado en la pre-maxila a nivel del tabique medio del proceso palatino. El foramen accesorio medio está ubicado en la parte anterior en M. c. crenulatum, M. c. longifolium, M. crenulatum "Sur", M. crenulatum "Amazonía", M. crenulatum "Guayanas", Phylloderma stenops y Phyllostomus discolor. Se ubica en la parte central o posterior en M. c. keenani, M. cozumelae, Tonatia saurophila, Trachops cirrhosus y Micronycteris megalotis. Mimon koepckeae, M. bennettii y Lophostoma occidentalis no exhiben foramen accesorio medio. Carácter usado por primera vez en una filogenia.

Carácter 63. Par de cavidades detrás de los incisivos superiores: ausente (0); o presente (1). Corresponde a dos pequeñas cavidades, ubicadas en la pre-maxila inmediatamente detrás de los incisivos. Están ausentes en el subgénero anteriormente llamado "Anthorhina", Phylloderma stenops, Phyllostomus discolor, Lophostoma occidentalis, Tonatia saurophila y Trachops cirrhosus. Están presentes en el subgénero Mimon y Micronycteris megalotis. Carácter usado por primera vez en una filogenia. 
Carácter 64. Amplitud de los bordes laterales del paladar: ligeramente amplios (0); o moderadamente amplios (1); o marcadamente amplios (2). El borde posterior del paladar está dividido por el interpterigoideo. Los bordes laterales son ligeramente amplios en M. crenulatum keenani "Ecuador", M. c. keenani "Venezuela", M. c. keenani "Panamá" y Micronycteris megalotis. Son moderadamente amplios en M. c. crenulatum, M. c. longifolium, M. crenulatum "Sur", M. crenulatum "Amazonía", M. crenulatum "Guayanas", M. c. keenani "Tumbes", el subgénero Mimon, Phylloderma stenops, Phyllostomus discolor y Trachops cirrhosus. Son marcadamente amplios en M. koepckeae, Lophostoma occidentalis y Tonatia saurophila. Carácter usado por primera vez en una filogenia.

Carácter 65. Presencia del proceso posterior del paladar: ausente (0); o presente (1). El proceso del paladar está presente en M. koepckeae, Trachops cirrhosus y Micronycteris megalotis. Es ausente en M. c. crenulatum, M. c. longifolium, M. crenulatum"Sur", M. crenulatum "Amazonía", M. crenulatum "Guayanas", M. c. keenani, el subgénero Mimon, Phylloderma stenops, Phyllostomus discolor, Lophostoma occidentalis y Tonatia saurophila. Este carácter fue incluido de manera combinada por Owen (1987; carácter 10) y Lim (1993; carácter 4). Fue usado con el mismo criterio por Simmons y Conway (2001; carácter 13).

Carácter 66. Alcance de la fosa mesopterigoidea: sobrepasa la mitad del interpterygoideo (0); o no sobrepasa la mitad del interpterygoideo (1). La fosa mesopterigoidea sobrepasa el punto medio del interpterigoideo en M. koepckeae, Trachops cirrhosus y Phyllostomus discolor. No sobrepasa el punto medio en M. c. crenulatum, M. c. longifolium, M. c. keenani, $M$. crenulatum "Sur", M. crenulatum "Amazonía", M. crenulatum "Guayanas", el subgénero Mimon, Phylloderma stenops, Lophostoma occidentalis, Tonatia saurophila y Micronycteris megalotis. Owen (1987; carácter 9), la extensión es expresada respecto al borde anterior de las órbitas. Lim (1993; carácter 4) hace referencia a la extensión del paladar respecto al interpterygoideo sin punto de referencia. Wetterer et al. (2000; carácter 44) describen los estados respecto al espacio interpterygoideo y molares.

Carácter 67. Forma de la fosa mesopterigoidea: en forma de " $V$ " (0); o en forma de " $U$ " (1). La fosa mesopterigoidea presenta forma de $V$ invertida en los representantes de M. koepckeae, M. cozumelae, Phyllostomus discolor, Phylloderma stenops, Lophostoma occidentalis, Trachops cirrhosus, Tonatia saurophila y Micronycteris megalotis (Figura 7e y g). Exhibe forma de $U$ invertida en los representantes de $M$. c. crenulatum, M. c. longifolium, $M$. c. keenani, M. crenulatum "Sur", M. crenulatum "Amazonía", M. crenulatum "Guayanas" у M. bennettii (Figura $7 f$ y h). Carácter usado por primera vez en una filogenia.

Carácter 68. Forma de la bullas timpánicas: muy angostas y cortas (0); o angostas y altas (1); o ancha y alta (2); o muy ancha y alta (3). Las bullas son muy angostas y cortas en el subgénero Mimon, Phylloderma stenops, Phyllostomus discolor y Lophostoma occidentalis (Figura $7 \mathrm{~g}$ y h). Son angostas y altas en M. koepckeae, Tonatia saurophila, Trachops cirrhosus y Micronycteris megalotis (Figura 7e). Son anchas y altas en M. c. crenulatum, M. c. longifolium, M. c. keenani, M. crenulatum "Amazonía", M. crenulatum "Guayanas" (Figura 7f). Son muy anchas y altas en M. crenulatum "Sur". Carácter usado por primera vez en una filogenia.

Carácter 69. Tamaño de la apertura del meato auditivo: grande (0); o pequeño (1). El meato auditivo es grande cuando ocupa casi la mitad del área del anillo auditivo, este carácter es exhibido en los representantes de M. crenulatum "Amazonía", M. cozumelae, Phylloderma stenops, Phyllostomus discolor, Tonatia saurophila y Trachops cirrhosus. La apertura del meato auditivo abarca menos de la mitad del área del anillo auditivo en los 
representantes de M. c. crenulatum, M. c. longifolium, M. c. keenani, M. crenulatum "Guayanas", M. bennettii, Lophostoma occidentalis y Micronycteris megalotis. Carácter usado por primera vez en una filogenia.

Carácter 70. Amplitud del basioccipital a la altura de las cócleas: ancho (0); o angosto (1). El basioccipital es muy amplio en M. c. crenulatum, M. c. longifolium, M. c. keenani, $M$. crenulatum "Amazonía", M. crenulatum “Guayanas", el subgénero Mimon, Phylloderma stenops, Phyllostomus discolor, Lophostoma occidentalis y Micronycteris megalotis. Es angosto en $M$. crenulatum "Sur", M. koepckeae, Tonatia saurophila y Trachops cirrhosus. Usado por Simmons y Conway (2001; carácter 25).

Carácter 71. Posición de las proyecciones laterales del basiesfenoides: distinguibles y perpendiculares al tabique del basiesfenoides (0); o distinguibles y convergentes hacia el tabique del basiesfenoides (1); o poco desarrolladas pero distinguibles y ligeramente convergentes (2). Las proyecciones del basiesfenoides son perpendiculares en $M$. koepckeae. Son distinguibles y convergentes hacia el tabique del basiesfenoides en M. c. crenulatum, $M$. c. longifolium, M. c. keenani, M. crenulatum "Sur", M. crenulatum "Amazonía" y M. crenulatum "Guayanas". Son poco desarrolladas pero distinguibles y ligeramente convergentes en el subgénero Mimon, Phylloderma stenops, Phyllostomus discolor, Lophostoma occidentalis, Tonatia saurophila, Trachops cirrhosus y Micronycteris megalotis. Carácter usado por primera vez en una filogenia.

Carácter 72. Profundidad de la cavidades del basiesfenoides: muy profundas (0); o moderadamente profundas (1); o poco profundas casi planas (2). Las cavidades son muy profundas en M. c. crenulatum, M. c. longifolium, M. crenulatum "Amazonía", M. crenulatum "Guayanas" y Phyllostomus discolor (Figura 7f). Son moderadamente profundas en M. c. keenani, M. crenulatum "Sur", M. koepckeae, Tonatia saurophila y Micronycteris megalotis (Figura 7e). Son poco profundas a planas en el subgénero Mimon, Phylloderma stenops, Lophostoma occidentalis y Trachops cirrhosus (Figura 7g y h). Owen (1987; carácter 13), además de los estado propuestos en el presente estudio, considera la ausencia de estas fosas como el estado más ancestral.

Carácter 73. Forma del tabique del basiesfenoides: alto y de borde romo (0); o alto y de borde afilado (1); o poco desarrollado de borde romo (2). El tabique del basiesfenoides es alto y de borde romo en M. c. crenulatum, M. c. keenani, M. crenulatum "Amazonía", M. crenulatum "Sur", el subgénero Mimon, Tonatia saurophila y Trachops cirrhosus. El tabique es alto y de borde afilado en M. c. longifolium, M. crenulatum "Guayanas", M. koepckeae, Phyllostomus discolor y Micronycteris megalotis. Phylloderma stenops y Lophostoma occidentalis exhiben el tabique poco desarrollado y romo. Carácter usado por primera vez en una filogenia.

Carácter 74. Desarrollo del proceso paraoccipital: pobremente desarrollado casi imperceptible (0); moderadamente desarrollado (1); o bien desarrollado (2). El paraoccipital es pobremente desarrollado en $M$. koepckeae y Micronycteris megalotis. Es moderadamente desarrollado en M. c. crenulatum, M. c. keenani, M. c. Iongifolium, M. crenulatum "Sur", M. crenulatum "Amazonía", M. crenulatum "Guayanas", Tonatia saurophila y Trachops cirrhosus. Es bien desarrollado en el subgénero Mimon, Phylloderma stenops, Phyllostomus discolor y Lophostoma occidentalis. Owen (1987; carácter 12), compara el desarrollo del proceso paraoccipital respecto al proceso mastoideo, considera ancestral la ausencia de la estructura y las fosas extremadamente profundas como estado derivado. Usado por Velazco (2005; carácter 20). 
Carácter 75. Cúspides accesorias del canino superior: ausentes (0); poco desarrolladas (1); o desarrolladas (2). Las cúspides del canino superior están ausentes en el subgénero Mimon, Phylloderma stenops, Phyllostomus discolor, Tonatia saurophila, Trachops cirrhosus y Micronycteris megalotis. Se encuentran poco desarrolladas en M. c. crenulatum, M. c. keenani, M. c. longifolium, M. crenulatum "Sur", M. crenulatum "Amazonía", M. crenulatum "Guayanas" y Lophostoma occidentalis. Se encuentran muy bien desarrolladas en M. koepckeae. Carácter usado por primera vez en una filogenia.

Carácter 76. Presencia de un surco profundo entre el hipocono y paracono del M1 y M2: ausente (0); o presente (1). Un surco profundo y muy bien definido entre el hipocono y el paracono de los molares M1 y M2 es exhibido en los representantes de M. crenulatum keenani, M. koepckeae, Lophostoma occidentalis, Trachops cirrhosus y Micronycteris megalotis; el surco es ausente en los representantes de M. c. crenulatum, M. c. longifolium, M. crenulatum "Sur", M. crenulatum "Amazonía", M. crenulatum"Guayanas", el subgénero Mimon, Phylloderma stenops, Phyllostomus discolor y Tonatia saurophila. Carácter usado por primera vez en una filogenia.

Carácter 77. Cíngulo lingual del segundo molar superior M2: ausente (0); o poco desarrollado (1); o desarrollado (2). El cíngulo del M2 es ausente en M. c. crenulatum, $M$. c. keenani "Venezuela", M. c. longifolium, M. crenulatum "Amazonía", el subgénero Mimon, Phyllostomus discolor, Lophostoma occidentalis, Tonatia saurophila y Trachops cirrhosus. Es poco desarrollado en M. koepckeae, M. c. keenani "Panamá", M. c. keenani "Ecuador", M. c. keenani "Tumbes", M. crenulatum "Guayanas", Phylloderma stenops y Micronycteris megalotis. En M. crenulatum "Sur" el cíngulo es notablemente más desarrollado. Velazco (2005: carácter 41) codificó dos estados para este carácter: ausente y presente.

Carácter 78. Forma de la cresta anterior del proceso coronoide: curva (0); o recta (1). El borde anterior del proceso coronoide de la mandíbula es de forma curva en los representantes de M. crenulatum "Sur", M. c. keenani "Tumbes", M. cozumelae, Phyllostomus discolor, Lophostoma occidentalis y Tonatia saurophila (Figura $8 \mathrm{~b}$ y c). El borde anterior exhibe forma recta en los representantes de M. koepckeae, M. c. longifolium, M. crenulatum "Amazonía", M. crenulatum “Guayanas", M. bennettii, Phylloderma stenops, Trachops cirrhosus y Micronycteris megalotis (Figura 8a y d). No se revisaron los especímenes de M. c. crenulatum, M. c. keenani "Panamá", M. c. keenani "Venezuela”, M. c. keenani "Ecuador" y M. crenulatum "Guayanas", por lo que fueron codificados como "?". Carácter usado por primera vez en una filogenia.

Carácter 79. Posición del proceso condiloide de la mandíbula: sobrepasa el alto de la encía (0); o no sobrepasa el alto de la encía (1). Corresponde a la posición del proceso condiloide, respecto al borde superior de la encía libre entre la hilera molar y el proceso coronoide. El proceso condiloide sobrepasa a la encía en M. c. crenulatum, M. c. longifolium, M. crenulatum "Sur", M. crenulatum "Amazonía", M. crenulatum "Guayanas", el subgénero Mimon, Phylloderma stenops, Phyllostomus discolor, Lophostoma occidentalis, Tonatia saurophila, Trachops cirrhosus y Micronycteris megalotis. En M. koepckeae y M. c. keenani el proceso no sobrepasa el alto de la encía. Carácter usado por primera vez en una filogenia.

Carácter 80. Tamaño del proceso angular de la mandíbula: corto (0); o largo (1). El tamaño del proceso angular es corto cuando, en vista dorsal, es cubierto por el proceso condiloide y largo cuando sobresale del proceso condiloide. Es corto en M. c. crenulatum, M. c. keenani, M. crenulatum "Sur", M. crenulatum "Amazonía", M. crenulatum "Guayanas", 
M. koepckeae, el subgénero Mimon, Phylloderma stenops, Phyllostomus discolor, Trachops cirrhosus y Micronycteris megalotis. Es largo en M. c. longifolium, Lophostoma occidentalis y Tonatia saurophila. Carácter usado por primera vez en una filogenia.

Carácter 81. Forma de la base posterior de la mandíbula: angular (0); o diagonal (1); o recto (2). El perfil posterior e inferior de la mandíbula es angular en $M$. c. crenulatum, $M$. c. keenani, M. c. longifolium, M. crenulatum "Sur", M. crenulatum "Amazonía" y M. crenulatum "Guayanas" (Figura 8b). Es diagonal en M. koepckeae, Lophostoma occidentalis, Tonatia saurophila, Trachops cirrhosus y Micronycteris megalotis (Figura 8a). Es recto en el subgénero Mimon, Phylloderma stenops y Phyllostomus discolor (Figura $8 \mathrm{c}$ y d). Carácter usado por primera vez en una filogenia.

Carácter 82. Presencia del incisivo inferior externo i2: ausente (0); o presente (1). El incisivo inferior externo i2 es ausente en todos los miembros del subgénero anteriormente llamado "Anthorhina", el subgénero Mimon, Lophostoma occidentalis y Tonatia saurophila. Está presente en Phylloderma stenops, Phyllostomus discolor, Trachops cirrhosus y Micronycteris megalotis. Pacheco y Patterson (1991; carácter 2) indica que la presencia de i2 es la condición primitiva del estado. Wetterer et al. (2000; carácter 54), usa codificación inversa.

Carácter 83. Número de lóbulos de los incisivos inferiores internos (i1): bilobados (0); o trilobados (1). Los incisivos inferiores internos (i1) son bilobados en M. koepckeae, Lophostoma occidentalis, Tonatia saurophila y Micronycteris megalotis. Son trilobados en $M$. c. crenulatum, M. c. keenani, M. c. longifolium, M. crenulatum "Sur", M. crenulatum "Amazonía", M. crenulatum "Guayanas", el subgénero Mimon, Phylloderma stenops, Phyllostomus discolor y Trachops cirrhosus. Usado por Pacheco y Patterson (1991; carácter 3), no codificaron los incisivos exteriores, porque estos tienden a desgastarse a temprana edad. Simmons y Conway (2001; carácter 34), codificaron este carácter para los incisivos externos como un carácter independiente.

Carácter 84. Presencia del tercer premolar inferior (p3): ausente (0); o presente (1). El premolar inferior p3 está ausente en todos los miembros del subgénero anteriormente llamado "Anthorhina", el subgénero Mimon y Phyllostomus discolor. Está presente en Phylloderma stenops, Lophostoma occidentalis, Tonatia saurophila, Trachops cirrhosus y Micronycteris megalotis. Usado por Wetterer et al. (2000; carácter 58), quienes además tomaron en cuenta el tamaño proporcional de $\mathrm{p} 3$ respecto a los otros premolares.

Carácter 85. Presencia de la cúspide accesoria distal secundaria en el premolar superior P4: ausente (0); o presente (1). La cúspide accesoria distal secundaria en el premolar superior P4 es ausente en todos los miembros del subgénero anteriormente llamado "Anthorhina", Phylloderma stenops, Phyllostomus discolor, Lophostoma occidentalis y Tonatia saurophila. Está presente en el subgénero Mimon, Trachops cirrhosus y Micronycteris megalotis. Usado por Wetterer et al. (2000; carácter 57) quienes además incluyeron el estado ambiguo.

Carácter 86. Compresión de los caninos inferiores: comprimidos, forma de vela náutica (0); o no comprimidos, forma piramidal (1). Los caninos inferiores están comprimidos en $M$. c. crenulatum, M. c. longifolium, M. crenulatum "Sur", M. crenulatum "Amazonía", M. crenulatum "Guayanas", M. c. keenani "Panamá", M. c. keenani "Venezuela", M. c. keenani "Ecuador", Phylloderma stenops, Lophostoma occidentalis y Trachops cirrhosus. No están comprimidos en M. koepckeae, M. c. keenani "Tumbes", el subgénero Mimon, Phyllostomus discolor, Tonatia saurophila y Micronycteris megalotis. Carácter usado por primera vez en una filogenia. 
Carácter 87. Compresión del cuarto premolar inferior - p4: Comprimido posteriormente, forma de vela náutica (0); o no comprimido, forma piramidal (1). El cuarto premolar inferior - p4 está comprimido en M. crenulatum keenani. No está comprimido en M. c. crenulatum, M. c. longifolium, M. crenulatum "Sur", M. crenulatum "Amazonía", M. crenulatum "Guayanas", M. koepckeae, el subgénero Mimon, Phylloderma stenops, Phyllostomus discolor, Lophostoma occidentalis, Tonatia saurophila, Trachops cirrhosus y Micronycteris megalotis. Carácter usado por primera vez en una filogenia.

Postcraneales. Carácter 88. Arreglo del tercer y quinto metacarpal: longitud del tercer metacarpal mayor que el quinto (0); o longitud de los metacarpales similar (1); o longitud del tercer metacarpal menor al quinto (2). La longitud del tercer metacarpal es menor al quinto en M. koepckeae, M. crenulatum keenani, el subgénero Mimon, Phylloderma stenops, Lophostoma occidentalis, Tonatia saurophila, Trachops cirrhosus y Micronycteris megalotis. La longitud de los metacarpales III y V es similar en M. crenulatum "Sur" y M. c. longifolium. En M. c. crenulatum, M. crenulatum "Amazonía", M. crenulatum "Guayanas" y Phyllostomus discolor el tercer metacarpal es más largo que el quinto. Usado por Velazco (2005; carácter 59) y Wetterer et al. (2000; carácter 84).

Carácter 89. Longitud relativa del calcar: igual o mayor a la longitud de la tibia (0); o menor a la longitud de la tibia pero más largo que la pata (1); o menor a la longitud de la tibia y de la pata (2). El calcar es de mayor longitud que la tibia en M. c. crenulatum, M. c. keenani, M. crenulatum "Amazonía", M. crenulatum "Sur", M. koepckeae y Micronycteris megalotis. El calcar es de menor longitud que la tibia pero mayor que la pata en M. c. longifolium, $M$. crenulatum "Guayanas", Lophostoma occidentalis, Tonatia saurophila y el subgénero Mimon. El calcar es menor que la longitud de la tibia y la pata en Phylloderma stenops, Phyllostomus discolor y Trachops cirrhosus. En Wetterer et al. (2000; carácter 87) hacen referencia a la longitud relativa del calcar sólo respecto a la pata.

Carácter 90. Punto de inserción del plagiopatagio: en el tobillo (0); o en el primer metatarsal (1). El plagiopatagio se inserta en el primer metatarsal de todos los representantes del subgénero anteriormente llamado "Anthorhina", Phylloderma stenops, Phyllostomus discolor, Lophostoma occidentalis, Tonatia saurophila y Micronycteris megalotis (Figura 6a). En contraste el plagiopatagio se inserta en el tobillo en el subgénero Mimon y Trachops cirrhosus (Figura 6b). Owen (1987; carácter 6) indica la inserción del plagiopatagio en la región de la tibia, del tarso y del metatarso (multiestado). Wetterer et al. (2000; carácter 88), además de la inserción en la pierna (tibia) hacen referencia a los diferentes puntos en el tarso donde se inserta el plagiopatagio, incluyendo el calcar. Velazco (2005; carácter 60) codifica dos estados para la inserción del plagiopatagio: en la región del tobillo y en el primer metatarsal. No estamos de acuerdo con Wetterer et al. (2000) respecto al punto de inserción del plagiopatagio en $M$. bennettii; éste se ubica indiscutiblemente en el tobillo.

Carácter 91. Longitud relativa de la cola: corta (0); o larga (1). Corresponden a la longitud relativa de la cola respecto a la longitud de la pata. La cola es larga, mayor a la longitud de la pata, en el subgénero anteriormente llamado "Anthorhina" y Micronycteris megalotis. El resto de taxones exhiben colas cortas, menores a la longitud de la pata. Usado por Wetterer et al. (2000; carácter 89). 


\section{Resultados}

Como resultado de la búsqueda exhaustiva se obtuvo un único árbol más parsimonioso de 306 pasos ( $I C=0.464$, IR $=0.675$ ), con 16 nodos soportados con el índice de Bremer; asimismo, en el árbol el valor promedio de Bootstrap es $78.90 \%$ y de Jacknife $81.18 \%$ (Figura 9). El árbol enraizado con Micronycteris megalotis muestra dos clados muy bien diferenciados. El primero agrupa a los otros miembros del grupo externo y al subgénero Mimon (Bootstrap $=66 \%$ y Jacknife $=72 \%$ ). El segundo está conformado por M. crenulatum y M. koepckeae, miembros del subgénero anteriormente llamado "Anthorhina", (Bootstrap = $95 \%$ y Jacknife =97), apoyando la monofilia del clado (Figura 9, rectángulo gris).

Figura 9. Árbol único más parsimonioso obtenido del análisis filogenético basado en caracteres no ordenados (306 pasos, $\mathrm{IC}=0.464, \mathrm{IR}=0.675$ ) El número de nodo se encuentra al lado izquierdo y debajo del nodo, por encima el valor de soporte de Bremer y un círculo que varía en tonos de gris para los valores de Bootstrap y Jacknife.

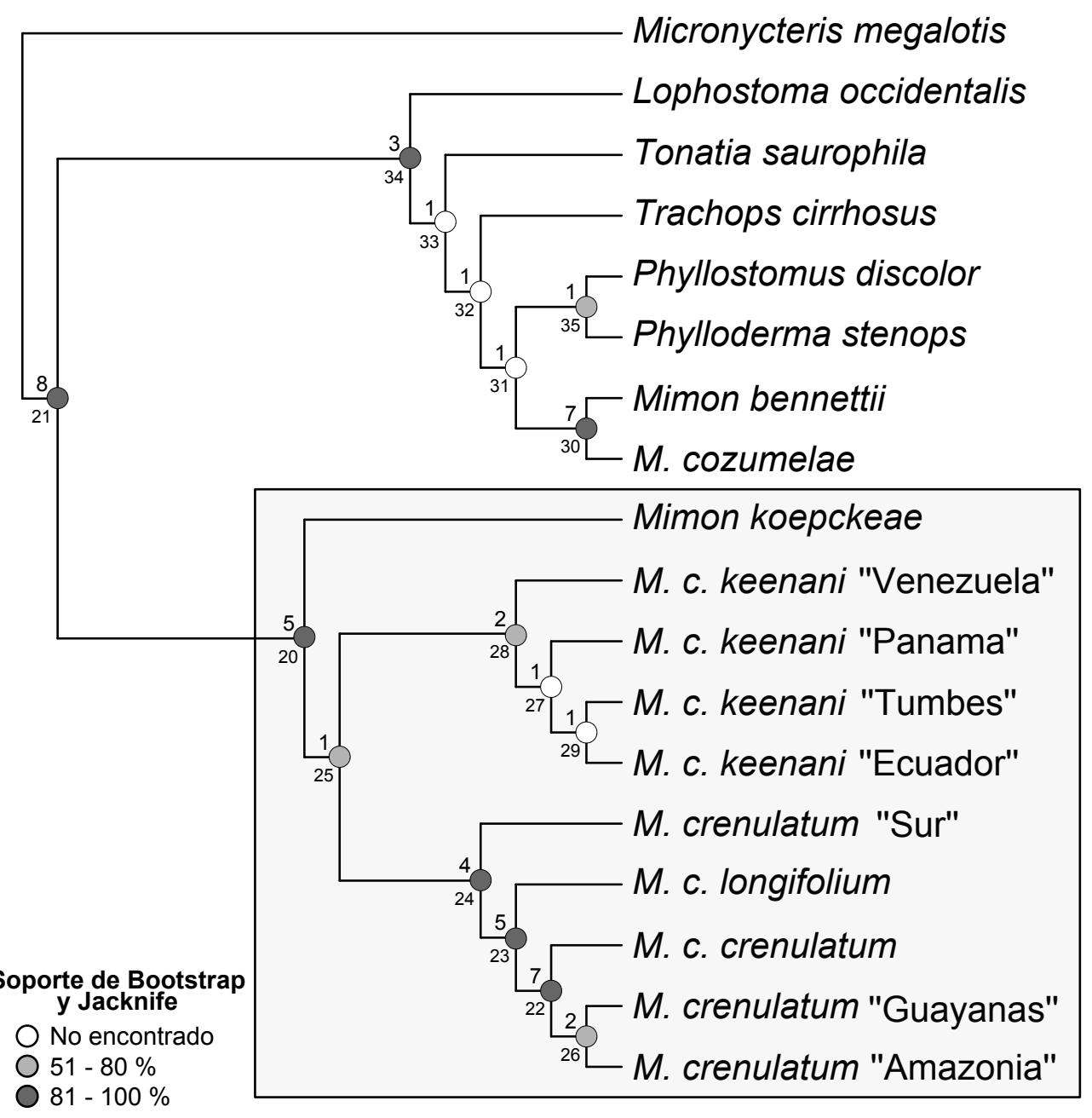

El árbol muestra que el género Mimon (sensu Simmons 2005) es polifilético. Los representantes del subgénero monofilético Mimon sensu estricto se encuentran en el nodo 30 (Bootstrap $=99 \%$ y Jacknife $=99 \%$ ), teniendo como grupo hermano al nodo 35 conformado por Phylloderma stenops y Phyllostomus discolor (Bootstrap $=55 \%$, Jacknife $=55 \%$ ).

El nodo 20 representa la monofilia muy bien respaldada del taxón anteriormente llamado "Anthorhina", conformada por Mimon koepckeae y el nodo 25, equivalente a Mimon crenulatum sensu lato (Bootstrap $=52 \%$ y Jacknife $=53 \%$ ). Este último está conformado por dos nodos: el nodo 28, equivalente a M. crenulatum keenani (Bootstrap $=80 \%$, Jacknife 
= $78 \%$ ) que agrupa a M. crenulatum keenani "Venezuela", M. crenulatum keenani "Panamá", $M$. crenulatum keenani "Tumbes" y M. crenulatum keenani "Ecuador"; y el nodo 24 (Bootstrap = $81 \%$, Jacknife $=87 \%$ ), conformado por M. crenulatum "Sur" y el nodo 23 (Bootstrap $=85 \%$, Jacknife $=88 \%$ ) conformado por M. c. longifolium y el nodo 22 (Bootstrap $=86 \%$, Jacknife $=$ $90 \%$ ) que a la vez agrupa a M. c. crenulatum y el nodo 26 (Bootstrap $=69 \%$, Jacknife $=74 \%)$ conformado por M. crenulatum "Amazonia" y M. crenulatum "Guayanas".

Discusión

Relaciones filogenéticas. La inclusión de todas la especies reconocidas dentro de Mimon ha permitido resolver las relaciones filogenéticas del género y mejorar la resolución de las relaciones dentro de Phyllostomidae. En nuestro análisis filogenético, Mimon sensu lato es un grupo polifilético (Figura 9), que contrasta con la definición de Wetterer et al. (2000) quienes indicaron que Mimon y "Anthorhina" conforman un grupo monofilético. Este resultado es congruente con los resultados de Dávalos et al. (2012) quienes, en base a caracteres moleculares, resuelven la polifilia de Mimon sensu lato, resaltando que Mimon sensu estricto no está relacionado con otros phyllostominos y recomiendan un mejor muestreo taxonómico para resolución de éstas relaciones. En este sentido, nuestro análisis incorporó los todos los taxa reconocidos para Mimon sensu lato y aquellos que anteriormente fueron indicados como grupos hermanos de "Anthorhina", como Lophostoma, Tonatia, Trachops Phyllostomus y Phylloderma (ver Patton y Baker 1978; Baker et al. 2000; 2003; Dávalos et al. 2012), encontrando que ninguno de ellos aparece como grupo hermano de "Anthorhina". La diferencia en la recuperación de grupos hermanos entre caracteres morfológicos y moleculares podría ser explicada por saturación o convergencia de caracteres tanto morfológicos como moleculares, como fue explicado por Dávalos et al. (2012). Sin embargo, en nuestra perspectiva estas diferencias corresponderían a árboles de genes incompletos e incongruencias en las topologías recuperadas por diferentes loci.

La obra de Miller (1907:129-130) lista a Mimon y "Anthorhina" como géneros, y describe que las características dentales y craneales de "Anthorhina" difieren de Mimon en cuanto a la presencia de un surco medio en el rostro (carácter 48), cavidades del basiesfenoides profundas (carácter 72) y bullas grandes (carácter 68). Miller (1907) no sugiere el tratamiento de los taxa como subgéneros o sinónimos. No obstante, Simpson (1945:57) incluye a "Anthorhina" dentro de Mimon sin proveer información. Más adelante Handley (1960:460) consideró que los caracteres que difieren entre el género anteriormente llamado "Anthorhina" y Mimon como el tamaño de los premolares superiores, incisivos inferiores, bullas (carácter 68) y orejas (carácter 30), la forma del arco cigomático (carácter 55), la densidad y tamaño del pelaje (caracteres 4 y 6) y presencia de pelos en la hoja nasal (carácter 11), no eran suficientes para distinguirlos siquiera como subgéneros; posición que fue compartida por Wetterer et al. (2000:141), quienes a pesar de contar con caracteres que respaldan las diferencias entre Mimon s.s. y "Anthorhina", mantuvieron la monofilia de Mimon s. I. con base en dos únicas sinapomorfías, como la presencia de dos vibrisas interramales (carácter 9) y la ausencia del incisivo inferior i2 (carácter 82) y un débil soporte del nodo. Consecuentemente, en la síntesis de Williams y Genoways (2008:281-282) se reconoce sólo al género Mimon s. l. caracterizado por presentar un solo incisivo y dos premolares en la mandíbula, cola que se extiende hasta la mitad del uropatagio y calcar más largo que la pata; combinación de caracteres que en nuestra opinión pueden ser exhibidos por otros taxa. 
Goodwin y Greehall (1961:236) consideraron que los caracteres que desestimó Handley (1960) eran suficientemente robustos para reconocer a "Anthorhina" y Mimon como subgéneros. Esta propuesta fue adoptada por Koopman (1994:76), quien además diferenció "Anthorhina" y Mimon por el punto de inserción del plagiopatagio en la pata (carácter 90). Si bien Simmons (2005:408 - 409) reconoce que Mimon s. I. está conformado por dos subgéneros, no brinda mayor información para la diferenciación de éstos. Por otra parte, Husson (1962) consideró, que contrariamente a lo propuesto por Handley (1960), los caracteres que distinguen a "Anthorhina" de Mimon son de relevancia para reconocerlos como géneros.

Los caracteres evaluados en este estudio, que incluyen los propuestos por Wetterer et al. (2000), muestran que el taxón anteriormente llamado "Anthorhina" exhibe características opuestas a la descripción original de Mimon s. s. (Gray 1847) como: la inserción del plagiopatagio en el metatarsal (carácter 90); patas más cortas que la cola (carácter 91) y densamente cubiertas por pelos largos (carácter 42); orejas cortas (carácter 30) y sin proyecciones laterales (carácter 31); y mentón sin protuberancias laterales (carácter 17) y sin surco profundo (carácter 18). Aproximación que respalda la propuesta de Hurtado et al. (2014), quienes consideran que M. crenulatum y M. koepckeae presentan caracteres que difieren de los descritos para distinguir Mimon de otros géneros. En consecuencia, basados en la evidencia de las relaciones interespecíficas y la monofilia del taxón anteriormente llamado "Anthorhina" (nodo 20) fuertemente respaldadas (Figura 9), así como las sinapomorfías de este nodo (Apéndice 2), proponemos reconocer a Mimon y el taxón anteriormente llamado "Anthorhina" como géneros plenos, coincidiendo con lo propuesto por Miller (1907) y Husson (1962). Sin embargo, debido a que la denominación "Anthorhina" no es considerada válida para este taxón (Gardner y Ferrel 1990; Simmons 2005; Williams y Genoways 2008), en el apartado de diagnosis taxonómica se propone un nuevo nombre.

En adición a las diferencias morfológicas, Hurtado et al. (2014) sugirieron que existe una distinción en el uso de hábitat y la composición de la dieta entre los géneros; así los integrantes de "Anthorhina" son insectívoros estrictos que se alimentan a nivel del sotobosque; mientras que los miembros de Mimon s.s. son más generalistas al alimentarse de otros invertebrados, pequeños vertebrados y frutos a nivel del sotobosque y dosel. Dado que estas conjeturas se desprenden como una inferencia de los datos dispersos en diferentes trabajos, recomendamos realizar los estudios de la composición de la dieta y del uso del hábitat que comprueben ésta hipótesis.

Respecto a las relaciones interespecíficas dentro de este taxón, observamos que éste diverge en dos nodos, el primero correspondiente a Mimon koepckeae (nodo 19) reforzando la evidencia que este taxón es una especie válida (Simmons y Voss 1998; Simmons 2005; Hurtado et al. 2014). El segundo (nodo 24) corresponde a los taxa dentro del grupo Mimon crenulatum (Figura 2), que hasta el momento son considerados subespecies o sinónimos de M. crenulatum (Koopman 1993; 1994; Simmons y Voss 1998; Simmons 2005; Williams y Genoways 2008). Basados en las diferencias morfológicas y el respaldo filogenético moderado del nodo 28 (Bootstrap $=77 \%$, Jacknife $=74 \%$ ), sugerimos que $M$. crenulatum keenani sea elevado a nivel de especie. Un mayor sustento incluyendo estadísticas estándar y análisis multivariados es tema de una próxima publicación. Por otro lado, M. c. longifolium y M. c. crenulatum no presentan mayor evidencia morfológica para ser consideradas especies plenas, por lo cual deberían ser tratadas como sinónimos, tal como lo propuso Handley 
(1962); de igual manera las poblaciones de la "Amazonía" y "Guayanas" corresponden a $M$. crenulatum s. s. Tomando en cuenta el soporte filogenético y la evidencia morfológica sugerimos profundizar el estudio de las poblaciones "Sur", ya que podría tratarse de una especie no descrita.

Filogeográficamente, la posición basal de M. koepckeae se respalda con la influencia de los Andes en la especiación de mamíferos sudamericanos (Patterson et al. 2012). Esta especie probablemente se aisló con el levantamiento de los Andes en el Mioceno tardío (Van Der Hammen 2000; Van Der Hammen y Hooghiemstra 2000), dejando al ancestro del nodo conformado por M. crenulatum keenani y M. c. crenulatum ampliamente distribuido hasta el levantamiento de los Andes septentrionales en el Pleistoceno (Van Der Hammen 2000) que aisló a M. c. keenani hacía el oeste (Cadenillas 2010). Paralelamente al levantamiento de los Andes septentrionales ocurría el levantamiento del Arco de Fitzcarraldo entre el Plioceno tardío y el Pleistoceno temprano (Espurt et al. 2010), el cual podría explicar la divergencia entre M. crenulatum y M. crenulatum "Sur".

Diagnosis taxonómica. Brindamos diagnosis completas de los nodos anteriormente incluidos dentro del género Mimon, basados en las optimizaciones de los estados de carácter en la filogenia de nuestro estudio. Las condiciones derivadas no ambiguas que representan sinapomorfias están mostradas en letras cursivas. Los caracteres diagnósticos se encuentran resaltados con letra negrita. Las condiciones ambiguas se encuentran en letras estándar.

\section{Familia Phyllostomidae Gray, 1825 Subfamilia Phyllostominae Gray, 1825 Género Mimon Gray, 1847}

Diagnosis corregida: Individuos de tamaño corporal grande. La banda de contraste del pelaje dorsal es tricoloreada. Línea dorsal ausente. La longitud del pelaje dorsal supera los 8 milímetros. El patrón de bandas de contraste ventral es unicoloreado. El pelaje es laxo. El hocico exhibe pelos densos y de longitudes variables. Exhibe 9 vibrisas a cada lado de la hoja nasal. Presenta dos vibrisas interramales. Las vibrisas laterales a la hoja nasal se hayan dispuestas en dos columnas por lado. Los pelos en el contorno del limbo de la hoja nasal están ausentes. La rama principal del trago exhibe pelos densos y largos. Los parches auriculares son blanquecinos e inconspicuos. La banda de pelos en los hombros puede estar presente o ausente. El pulgar es desnudo. El primer tercio del antebrazo está cubierto de pelos. El mentón es protuberante. El mentón exhibe un surco medio muy profundo. Las ornamentaciones en el mentón se hayan presentes. Las papilas submentales son dos por lado y de forma alargada. Las almohadillas de la vibrisas son ligeramente globosas. La longitud de la hoja nasal es mayor a la amplitud. La hoja nasal es de forma acorazonada, ancha en la parte media. Los bordes de la hoja nasal no presentan crenulaciones. Hoja nasal no pigmentada. El borde anterior de la herradura no exhibe proyecciones de piel libre. La punta de la rama principal del trago es aguda. La rama intermedia del trago es plana y delgada. La rama inferior del trago es suave. La longitud de la oreja supera los 30 milímetros. Las orejas son de forma lanceolada con las puntas divergentes hacia el exterior. Los pliegues de la oreja son muy bien definidos. La pigmentación de la oreja es completa. La textura de la oreja es suave y translúcida. Los bordes externos de la oreja son delgados y lisos. Las protuberancias internas del lóbulo interno de la oreja son esparcidas y poco desarrolladas. 
El lóbulo interno de la oreja es poco desarrollado. El pliegue de la base exterior de la oreja es muy desarrollado. La glándula gular es ausente. Puntas de las alas despigmentadas. Planta de la pata no pigmentada. Los pelos en el dorso de la pata son esparcidos y cortos. El peine de pelos en el uropatagio es ausente. No presenta depresión nasal. La premaxila no exhibe el borde anterior dorsal elevado. Los nasales son largos. Las crestas de los incisivos superiores son convergentes pero sin unirse. La depresión media rostral es ausente. La raíz maxilar del cigoma es plana. La caja craneana es inflamada anteriormente. El borde posterior de la caja craneana es redondeada. La cresta sagital es poco desarrollada. El largo relativo del rostro equivale a un tercio de la longitud del cráneo. La longitud del cráneo es mayor a 25 milímetros. El arco cigomático es delgado y angosto. La amplitud de la constricción postorbital es más angosta que el espacio entre los caninos. El paladar es más angosto que la región postorbital. La superficie del paladar es siempre ligeramente cóncava. La premaxila se encuentra en el mismo plano del paladar. El borde posterior de la premaxila no exhibe muescas. El borde medio del proceso palatino en la premaxila puede ser angosto o ancho. El foramen accesorio medio puede estar presente o ausente. Un par de forámenes accesorios detrás de los incisivos es exhibido siempre. El borde de los lados externos del paladar es moderadamente amplio. El proceso posterior del paladar está siempre ausente. Borde anterior de la fosa mesopterigoidea no sobrepasa la mitad del mesopteriogoideo. La fosa meso pterigoidea exhibe forma de " $\mathrm{U}$ " $\mathrm{y}$ "V". Bullas timpánicas muy cortas y muy angostas. La apertura del meato auditivo es grande o pequeña. El basioccipital es angosto a la altura de las cócleas. Los tabiques laterales del basiesfenoides son poco desarrolladas pero distinguibles. Las cavidades del basiesfenoides son poco profundas, casi planas. El tabique medio del basiesfenoides es poco desarrollado y de borde romo. El paraoccipital está siempre bien desarrollado. Los caninos superiores no exhiben cúspides accesorias. El surco medio entre el hipocono y el paracono de los molares M1 y M2 está siempre ausente. El molar M2 no exhibe cíngulo lingual. La cresta anterior del proceso coronoide puede ser recta o curvada. El proceso condiloide no sobrepasa el borde superior de la encía. El proceso angular de la mandíbula es corto. Perfil posterior de la mandíbula plana. Incisivo externo de la mandíbula está siempre ausente. Los incisivos inferiores son siempre trilobados. El tercer premolar está siempre ausente. La cúspide secundaria del cuarto premolar está siempre presente. Los caninos inferiores y los premolares p4 no exhiben compresión, son de forma piramidal. La longitud del tercer metacarpal es menor a la del quinto. La longitud del calcar es menor a la longitud de la tibia, pero mayor a la de pata. El plagiopatagio se haya inserto a la altura de la tibia, en la base del pie. La longitud de la cola es más corta que la pata.

Contenido: Mimon bennettii y M. cozumelae.

Distribución: Mimon se encuentra distribuido desde la costa Atlántica al sur de México hasta el sur de Brazil (el presente estudio; Williams y Genoways 2008). Mimon bennettii se restringe a Sudamérica, presentando dos poblaciones que podrían conformar taxa diferentes (Williams y Genoways 2008; P. M. Velazco comm.per.), una de ellas al norte del rango de distribución en ecosistemas de Orinoquia, tierras altas y bajas de las Guayanas, y parte norte de la Amazonia, y otra al sur en ecosistemas de Cerrado y Bosques del Atlántico (sensu Josse et al. 2003; Sayre 2008). Por otro lado, M. cozumelae se restringe a América central desde el sur de México hasta el noreste de Colombia, en los ecosistemas mesoamericanos húmedos (sensu Josse et al. 2003; Sayre 2008). 


\section{Género Gardnerycteris gen. nov.}

http://zoobank.org/NomenclaturalActs/D23362A5-FFC0-4D4F-95F1-FEFDB6CC9F28

Phyllostoma E'. Geoffroy St.-Hilaire, 1803:61; especie tipo de Phyllostoma crenulata

Mimon [(Anthorhina)]: Cabrera, 1958:66; primera combinación errónea.

Anthorhina: Husson, 1962:94; asignación errónea.

Especie tipo: Gardnerycteris koepckeae (Gardner y Patton 1972)

Etimología: En honor a Alfred L. Gardner, por la contribución realizada al conocimiento de los murciélagos Neotropicales.

Contenido: Garderycteris koepckeae y G. crenulatum.

Diagnosis: Individuos de tamaño corporal pequeño, no sobrepasan los $90 \mathrm{~mm}$ de longitud cabeza cuerpo. La banda de contraste del pelaje dorsal es unicoloreada o bicoloreda. La línea dorsal es polimórfica, puede estar ausente, ser tenue o muy marcada. Pelaje dorsal de longitud mediana entre 6.5 y 7.5 milímetros. La banda de contraste del pelaje ventral es bicoloreada o tricoloreada. El pelaje corporal es denso o laxo. Hocico con escasos pelos cortos y blanquecinos, dando la apariencia de piel desnuda. Exhibe de 6 a 7 vibrisas a cada lado de la hoja nasal. Presenta dos vibrisas interramales. Las vibrisas laterales a la hoja nasal se hayan dispuestas en una sola columna por lado. Pelos largos distribuidos en todo el contorno del limbo de la hoja nasal. La rama principal del trago exhibe pelos escasos y cortos o densos y largos. Los parches auriculares son polimórficos, varían de blanquecinos e inconspicuos a amarillentos y muy conspicuos. La banda de pelos en los hombros está siempre ausente. El pulgar siempre está cubierto de pelos. El primer tercio del antebrazo está siempre desnudo. El mentón es no protuberante. El mentón exhibe un surco medio medianamente profundo o profundo. Las ornamentaciones en el mentón están siempre ausentes. Las papilas submentales son circulares, dos centrales y cinco o seis por cada lado dispuesta de manera oblicua. Las almohadillas de las vibrisas son ligeramente globosas o globosas. La longitud de la hoja nasal equivale a dos veces o más el ancho de ésta. La hoja nasal es angosta y lanceolada. Los bordes de la hoja nasal exhiben siempre crenulaciones. La hoja nasal puede estar pigmentada o no. Borde anterior de la herradura de la hoja nasal desarrollado y libre, a manera de un ribete de piel. La punta de la rama principal del trago tiene forma aguda o redondeada. La rama intermedia del trago es globosa y engrosada. La rama inferior del trago es pronunciada o muy pronunciada. Oreja de longitud mediana entre 23 y 26 milímetros. Las orejas son de forma lanceolada con las puntas paralelas sin proyecciones. Los pliegues de la oreja son ligeramente definidos. La oreja exhibe la mitad externa pigmentada y la mitad interna no pigmentada. Las orejas son carnosas. Los bordes externos de la oreja son engrosados o delgados y lisos. Las protuberancias internas del lóbulo interno de la oreja son conglomeradas y desarrolladas o esparcidas y poco desarrolladas. El lóbulo interno de la oreja es poco desarrollado o desarrollado. El pliegue de la base exterior de la oreja es escasamente desarrollado. La glándula gular está siempre presente. Puntas de las alas pigmentadas o despigmentadas. Planta de la pata siempre pigmentada. Los pelos en el dorso de las patas son densos y largos. El peine de pelos en el uropatagio es polimórfico puede estar ausente o ser corto o abundante. La depresión nasal puede ser en forma de omega o V. Borde anterior dorsal de la premaxila ligeramente elevado. Los huesos nasales son siempre cortos. Las crestas de los incisivos superiores son convergentes, en algunos casos éstas se unen en la base. La depresión media rostral puede estar ausente o presente. La raíz maxilar del cigoma es ligeramente 
inflamada o muy inflamada. La caja craneana es no inflamada anteriormente. El borde posterior de la caja craneana es redondeado o anguloso. La cresta sagital es polimórfica varía de poco desarrollada a muy desarrollada. El largo relativo del rostro equivale a un cuarto o un tercio la longitud del cráneo. La longitud del cráneo es menor a 22.5 milímetros. El arco cigomático es aplanado lateralmente. La amplitud de la constricción postorbital es más angosta que el espacio entre los caninos. El paladar es más angosto o más ancho que la región postorbital. El paladar exhibe superficie cóncava o ligeramente cóncava. La premaxila se encuentra por debajo del plano del paladar. El borde posterior de la premaxila siempre exhibe muescas. El borde medio del proceso palatino de la premaxila puede ser angosto o ancho. El foramen accesorio medio, puede estar presente o ausente. Un par de forámenes accesorios detrás de los incisivos es exhibido siempre. El borde de los lados externos del paladar es moderadamente amplio. El proceso posterior del paladar está ausente o presente. Borde anterior de la fosa mesopterigoidea sobrepasa o no sobrepasa la mitad del mesopterigoideo. La fosa mesopterigoidea exhibe forma de $\mathrm{U}$ y $\mathrm{V}$. Bullas timpánicas siempre altas y de angostas a anchas. La apertura del meato auditivo es grande o pequeña. El basioccipital puede ser angosto o ancho a la altura de las cócleas. Los tabiques laterales del basiesfenoides son siempre desarrollados. Las cavidades del basiesfenoides son muy profundas o moderadamente profundas. El tabique medio del basiesfenoides es alto y de borde romo o afilado. El paraoccipital está siempre de poco a moderadamente desarrollado. Los caninos superiores exhiben cúspides accesorias. El surco medio entre el hipocono y el paracono de los molares M1 y M2 puede estar ausente o presente. El cíngulo lingual de molar M2 puede estar de ausente a desarrollado. La cresta anterior del proceso coronoide puede ser recta o curvada. El proceso condiloide puede sobrepasar o no el borde superior de la encía. El proceso angular de la mandíbula es corto o largo. Perfil posterior de la mandíbula de forma de talón o diagonal. Incisivo externo de la mandíbula está siempre ausente. Los incisivos inferiores son bilobados o trilobados. El tercer premolar está siempre ausente. La cúspide secundaria del cuarto premolar está siempre ausente. Los caninos inferiores y los premolares p4 pueden estar comprimidos o no. La longitud del tercer metacarpal puede ser menor, igual o mayor a la del quinto. La longitud del calcar es igual o mayor a la longitud de la tibia. El plagiopatagio se haya inserto en el tarso. La longitud de la cola es más larga que la pata.

Distribución: Gardnerycteris es un género sudamericano, ampliamente distribuido desde el sur de Panamá hasta el sur de Brasil y noreste de Bolivia (el presente estudio; Williams y Genoways 2008). Gardnerycterys crenulatum crenulatum se distribuye desde el noreste de Sudamérica hasta el sur de Brasil (el presente estudio; Handley 1960; Husson 1962; Simmons 2005; Williams y Genoways 2008), en los ecosistemas de Orinoquia, Guayanas, Amazonia, Cerrado y Bosque Atlántico (sensu Josse et al. 2003; Sayre 2008); G. crenulatum longifolium se distribuye en los bosques premotanos de la vertiente nororiental de Perú (el presente estudio; Koopman 1978); y G. crenulatum "Sur" distribuida en los bosques premontanos de la vertiente suroriental de Perú hasta el norte de los Bosques montanos de Bolivia (el presente estudio). Gardnerycteris crenulatum keenani se restringe al noroeste de Sudamérica, desde el sur de Panamá hasta el norte de Perú (el presente estudio; Handley 1962), en los Bosques Secos y Lluviosos del Pacífico (sensu Josse et al. 2003; Sayre 2008). Gardnerycteris koepckeae está restringida a los Bosques Montanos del centro de la vertiente oriental Peruana (Hurtado et al. 2014). 
Agradecimientos

Agradecemos a R. Cadenillas, C. Jiménez y E. Rengifo por sus valiosos comentarios en las primeras revisiones. A B. D. Patterson, P. M. Velazco y G. P. Servat por su apoyo académico y por brindar las facilidades para visitar las colecciones científicas revisadas. Este trabajo fue parcialmente patrocinado por el Comité de Becas del Field Museum of Natural History - FMNH, la beca CONICYT-PCHA/Doctorado Nacional/2014-63140131, convenio MECESUP AUS1203 y el FINCYT a NH y el financiamiento parcial de las becas 111001031 y 121001061 del CSI-UNMSM a VP.

Literatura citada

Baker, R. J., S. R. Hoofer, C. A. Porter, y R. A. Van Den Bussche. 2003. Diversification among New World leaf-nosed bats: an evolutionary hypothesis and classification inferred from digenomic congruence of DNA sequence. Occasional Papers of the Museum of Texas Tech University 230:1-32.

Baker, R. J., C. A. Porter, J. C. Patton, y R. A. Van Den Bussche. 2000. Systematics of bats of the family Phyllostomidae based on RAG2 DNA sequences. Occasional Papers of the Museum of Texas Tech University 202:1-16.

Brunet-Rossinni, A. K., y G. S. Wilkinson. 2009. Methods for age estimation and the study of senescence in bats. Pp. 315-325 en Ecological and behavioral methods for the study of bats (Kunz, T. H., y S. Parsons, eds.). Johns Hopkins University Press. Baltimore, EE.UU.

Cabrera, A. 1958. Catálogo de los mamíferos de América del Sur I. Revista del Museo Argentino de Ciencias Naturales "Bernardino Rivadavia", Ciencias Zoológicas 4:1308.

Cadenillas, R. 2010. Diversidad, ecología y análisis biogeográfico de los murciélagos del Parque Nacional Cerros de Amotape, Tumbes Perú. Tesis para optar el grado de Magíster en Zoología, Universidad Nacional Mayor de San Marcos. Lima, Perú.

Dávalos, L. M., A. L. Cirranello, J. H. Geisler, y N. B. Simmons. 2012. Understanding phylogenetic incongruence: lessons from phyllostomid bats. Biological Reviews 87:991-1024.

Espurt, N., P. Baby, S. Brusset, M. Roddaz, W. Hermoza, y J. Barbarand. 2010. The Nazca Ridge and uplift of the Fitzcarrald Arch: implications for regional geology in northern South America. Pp. 89-100 en A look into the past (Hoorn, C., y F. P. Wesselingh, eds.). Wiley-Blackwell Press. West Sussex, U.K.

Gardner, A. L. 2008. Family Phyllostomidae. Pp. 207-208 en Mammals of South America, Volume 1: Marsupials, Xenarthrans, Shrews, and Bats (Gardner, A. L., ed.). The University of Chicago Press. Chicago, EE.UU.

Gardner, A. L., y J. L. Patton. 1972. New species of Philander (Marsupialia: Didelphidae) and Mimon (Chiroptera: Phyllostomidae) from Peru. Occasional Papers of the Museum of Zoology of Louisiana State University 43:1-12.

Gardner, A. L., y C. S. Ferrel. 1990. Comments on the nomenclature of some neotropical bats (Mammalia: Chiroptera). Proccedings of the Biological Society of Washington 103:501-508. 
Gianninı, N. P., y N. B. Simmons. 2007. The Chiropteran Premaxilla: A Reanalysis of Morphological Variation and its Phylogenetic Interpretation. American Museum Novitates 3585:1-44.

Goloboff, P. A., J. S. FarRis, y K. C. Nixon. 2008. TNT, a free program for phylogenetic análisis. Cladistics 24:774-786.

Goodwin, G. G., AND A. M. Greenhall. 1961. A review of the bats of Trinidad and Tobago: descriptions, rabies infection, and ecology. Bulletin of the American Museum of Natural History 122:187-302.

GRAY, J.E. 1847. Characters of six new genera of bats not hitherto distinguished. Proceedings of the Zoological Society of London 1847:14-16.

Gregorin, R., G. L. Capusso, y V. R. Furtado. 2008. Geographic distribution and morphological variation in Mimon bennettii (Chiroptera, Phyllostomidae). Iheringia, Série Zoologia 98:404-411.

Handley, C. O. 1960. Descriptions of new bats from Panamá. Proccedings of the United States National Museum 112:459-479.

Husson, A. M. 1962. The bats of Suriname. Zoologische Verhandelingen, Rijksmuseum van Natuurlijke Historie 58:1-282.

Hurtado, N., E. Arias, y V. Pacheco. 2014. Redescription of Mimon koepckeae (Chiroptera: Phyllostomidae). Zoologia 31:377-388.

Jones, J. K., JR., y D. C. Carter. 1976. Annotated checklist with keys to subfamalies and genera. Pp. 7-38 en Biology of bats of the New World Family Phyllostomidae Part I (Baker, R. J., J. K. Jones, Jr., y D. C. Carter, eds.). Special Publications of the Museum of Texas Tech University 10:1-218.

Josse, C., G. Navarro, P. Comer, R. Evans, D. Faber-Langendoen, M. Fellows, G. Kittel, S. Menard, M. Pyne, M. Reid, K. Schulz, K. Snow, y J. Teague. 2003. Ecological Systems of Latin America and the Caribbean: A Working Classification of Terrestrial Systems. NatureServe. Arlington, EE.UU.

Koopman, K. F. 1976. Zoogeography. Pp. 39-47 en Biology of bats of the New World Family Phyllostomidae Part I (Baker, R. J., J. K. Jones, Jr., y D. C. Carter, eds.). Special Publications of The Museum of Texas Tech University 10:1-218.

Koopman, K. F. 1978. Zoogeography of Peruvian bats with special emphasis on the role of the Andes. American Museum Novitates 2651:1-33.

Koopman, K. F. 1993. Order Chiroptera. Pp. 137-241 en Mammal species of the World, a taxonomic and geographic reference, 2nd ed. (Wilson, D. E., y D. M. Reeder, eds.). Smithsonian Institution Press. Washington, EE.UU.

Koopman, K. F. 1994. Chiropteran systematics. Volume 8, Part 60. Pp. 1-217 en Handbuch der Zoologie (Niethammer, J., H. Schliemann, y D. Starck, eds.). Walter de Gruyter Press. Berlin, Alemania.

LıM, B. K. 1993. Cladistic reappraisal of neotropical Stenodermatine bat phylogeny. Cladistics 9:147-165.

Mılıer, G. S. 1907. The families and genera of bats. Bulletin of the United Stated National Museum 57:1-282.

Ortega, J., y H. T. Arita. 1997. Mimon bennettii. Mammalian Species 549:1-4.

Owen, R. D. 1987. Phylogenetic analyses of the bat subfamily Stenodermatinae (Mammalia: Chiroptera). Special Publications of The Museum of Texas Tech University 26:1-65. 
Pacheco, V., y B. D. Patterson. 1991. Phylogenetic relationships of the New World bat genus Sturnira (Chiroptera: Phhyllostomidae). Bulletin of the American Museum of Natural History 206:101-121.

Pacheco, V., y B. D. Patterson. 1992. Systematics and biogeographic analyses of four species of Sturnira (Chiroptera: Phyllostomidae), with emphasis on Peruvian forms. Pp. 57-81 en Biogeografia, ecología y conservación del bosque montano en el Perú (Young, K. R., y N. Valencia, eds.). Editorial de la Universidad Nacional Mayor de San Marcos. Lima, Perú.

Patterson, B. D., S. Solari, y P. M. Velazco. 2012. The role of the Andes in the diversification and biogeography of Neotropical mammals. Pp. 351-378 en Bones, clones, and biomes: the history and geography of Recent Neotropical mammals (Patterson, B. D., y L. P. Costa, eds.). University of Chicago Press. Chicago, EE.UU.

Patton, J. C., Y R. J. Baker. 1978. Chromosomal homology and evolution of Phyllostomatoid bats. Systematic Zoology 27: 449-462.

Sayre, R., J. Bow, C. Josse, L. Sotomayor, y J. Touval. 2008. Chapter 9: Terrestrial Ecosystems of South America. Pp. 131-152 en North America land cover Summit (Smith, J. H., ed.). Association of American Geographers Press. Wahington, EE.UU.

Simmons, N. B. 2005. Order Chiroptera. Pp. 312-529 en Mammal species of the World: a taxonomic and geographic reference, Third Edition, Volume 1 (Wilson, D. E., y D. M Reeder, eds.). Johns Hopkins University Press. Baltimore, EE.UU.

Simmons, N. B., y T. M. Conway. 2001. Phylogenetic Relationships of Mormoopid bats (Chiroptera: Mormoopidae) based on morphological data. Bulletin of the American Museum of Natural History 258:1-97.

Simmons, N. B., y R. S. Voss. 1998. Bats of Paracou. Bulletin of the American Museum of Natural History 237:1-219.

Simpson, G. G. 1945. The principles of classification and a classification of mammals. Bulletin of the American Museum of Natural History 85:1-350.

Van Den Bussche, R. A. 1989. Systematic study of the genera of the New World leaf-nosed bat family Phyllostomidae: Cladistical analisis of site variation in the ribosomal DNA cistron. Dissertation in Zoology submitted to the Graduate Faculty of Texas Tech University in Partial Fulfillment of the Requirements for the Degree of Doctor of Philosophy.

Van der Hammen, T. 2000. Aspectos de historia y ecología de la biodiversidad norandina y amazónica. Revista de la Academia Colombiana de Ciencias 24:231-245.

Van der Hammen, T., y H. Hooghiemstra. 2000. Neogene and Quaternary history of vegetation, climate, and plant diversity in Amazonia. Quaternary Science Reviews 19:725-742.

Velazco, P. M. 2005. Morphological phylogeny of the bat genus Platyrrhinus Saussure, 1860 (Chiroptera: Phyllostomidae) with the description of four new species. Fieldiana Zoology 105:1-53.

WIEns, J. J. 2000. Phylogenetic analysis of morphological data. Smithsonian Institution Press. Washington, EE.UU.

Williams S. L., y H. H. Genoways. 2008. Subfamily Phyllostominae. Pp. 255-299 en Mammals of South America, Volume 1: Marsupials, Xenarthrans, Shrews, and Bats (Gardner, A. L., ed.). The University of Chicago Press. Chicago, EE.UU. 
Wetterer, A. L., M. V. Rockman, y N. B. Simmons. 2000. Phylogeny of Phyllostomid Bats (Mammalia: Chiroptera): data from diverse morphological systems, sex chromosomes, and restriction sites. Bulletin of American Museum of Natural History 248:1-200.

Sometido: 18 de septiembre de 2014

Revisado: 20 de noviembre de 2014

Aceptado: 12 de diciembre de 2014

Editor asociado: Sergio Solari 
Especímenes examinados. Los repositorios están depositados en el Museo de Historia Natural de la Universidad Nacional Mayor de San Marcos (MUSM), American Museum of Natural History (AMNH), Field Museum of Natural History (FMNH) y National Museum of Natural History (NMNH).

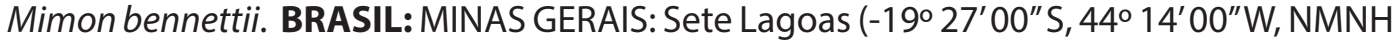

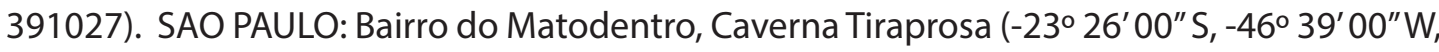
AMNH 256294). COLOMBIA: CORDOBA: Tierralta: Socorre, cabecera Río Sinu (70 51' 00" N, -760 17' 00"W, FMNH 69425-69427).

Mimon cozumelae. BELIZE: CAYO DISTRICT: $05 \mathrm{~m}$ West Augustine, un cueva a lo largo del Río Frío (16 58'00" N, -88 59' 27"W, FMNH 58152-58153). Carretera Oeste de Barton Creek (170 12' 00" N, -88० 57' 00" W, FMNH 58155-58156, 108764-108766). Churchyard, granja Glenwood (170 17'00"N , -88 34'00"W, FMNH 58154). Listowel School (Baking Pot) por el Río

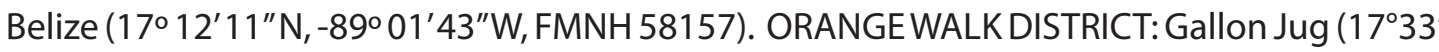
$\left.00^{\prime \prime} \mathrm{N},-89^{\circ} 01^{\prime} 00^{\prime \prime} \mathrm{W}, \mathrm{AMNH} 274575\right)$. Lamanai (170 45' 50" N, -88 39' 00" W, AMNH 277692). TOLEDO DISTRICT: Aguacate, por Creek (16 $\left.16^{\circ} 12^{\prime \prime} \mathrm{N},-89^{\circ} 05^{\prime} 24^{\prime \prime} \mathrm{W}, \mathrm{FMNH} 108767\right)$. Crique Negro (15० 58' 00" N, -89॰ 06' 00" W, NMNH 506467). Pueblo Viejo ( $16^{\circ} 12^{\prime} 19^{\prime \prime} \mathrm{N},-89^{\circ} 08^{\prime} 30^{\prime \prime}$

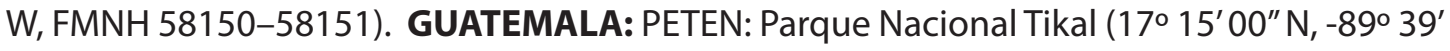
00"W, FMNH 58567). MÉXICO: CHIAPAS: Palenque: Palenque (170 30' 33" N, -910 58' 56" W, FMNH 150630-150631). OAXACA: Itsmo: Juchitan, 20 millas al norte de Matías Romero (170 $03^{\prime} 03^{\prime \prime} \mathrm{N},-95^{\circ} 01^{\prime} 00^{\prime \prime} \mathrm{W}, \mathrm{AMNH}$ 185862-185872). YUCATAN: Mérida: Buenavista, Xbac (210 $15^{\prime} 00^{\prime \prime} \mathrm{N},-88^{\circ} 49^{\prime} 30^{\prime \prime} \mathrm{W}, \mathrm{FMNH}$ 5845). PANAMÁ: Bocas del toro: Almirante: Changuinola (9॰ $26^{\prime} 00^{\prime \prime} \mathrm{N},-82^{\circ} 31^{\prime} 00^{\prime \prime} \mathrm{W}, \mathrm{NMNH} 315220$ ).

Gardnerycteris koepckeae. PERÚ: AYACUCHO: La Mar: Huanhuachayo (-12 44'00" S, $-73^{\circ}$

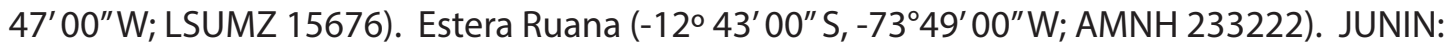
Chanchamayo: Santuario Nacional Pampa Hermosa, Podocarpus (-10 59' 49.2" S, $-75^{\circ} 25^{\prime}$ 57.1"W; MUSM 41327).

Gardnerycteris crenulatum keenani. ECUADOR: MANABI: Sucre: Bahía de Caraquez $\left(0^{\circ} 36^{\prime}\right.$ $00^{\prime \prime} \mathrm{S},-80^{\circ} 26^{\prime} 00^{\prime \prime} \mathrm{W}, \mathrm{AMNH}$ 64537-64541). GUATEMALA: PETEN: Parque Nacional Tikal (170 $15^{\prime} 00^{\prime \prime} \mathrm{N},-89^{\circ} 39^{\prime} 00^{\prime \prime} \mathrm{W}, \mathrm{FMNH}$ 58568-58569). PANAMÁ: Bocas del Toro: Guabito: Sibube

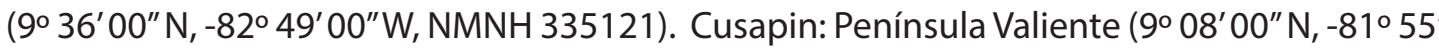
00"W, NMNH 57846). PERÚ: TUMBES: Tumbes: Pampas de Hospital: Quebrada Angostura

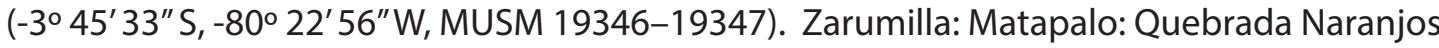

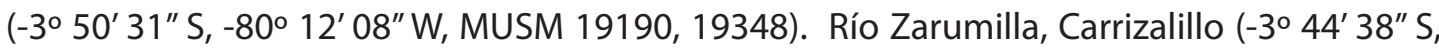

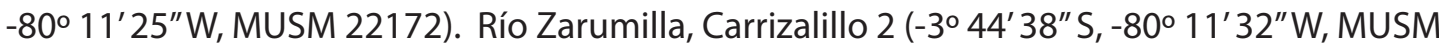
22173). VENEZUELA: FALCON: Bolívar: Río Tocuyo (10 $10^{\circ} 00^{\prime \prime} \mathrm{N},-69^{\circ} 56^{\prime} 00^{\prime \prime} \mathrm{W}$, AMNH 130687-130699, 130724, 131085-131086).

Gardnerycteris crenulatum longifolium. PERÚ: Amazonas: Condorcanqui: El Cenepa: Condorcanqui, P.V. 22 (Falso Paquisha) Cordillera el Cóndor (-4 01'01"S, -78 24'00"W, MUSM 351). HUÁNUCO: Puerto Inca: Río Llullapichis, tributario del Río Pachitea (-9³7'00" S, -74

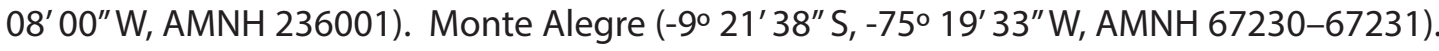
PASCO: Oxapampa: Palcazu: Cerro Chontiya, $5 \mathrm{Km}$ Oeste Shiringamazu, carretera a Iscosazin

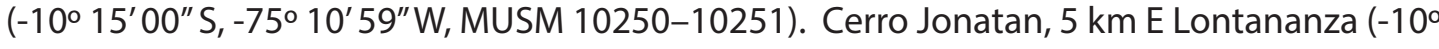
21'57"S, -750 11'23"W, MUSM 10252). Hacienda Roca-Lux, Lontananza, Río Mucñis, afluente

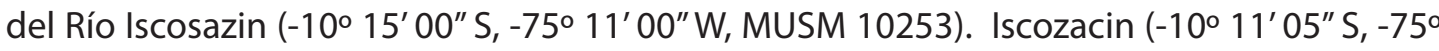


08' 43" W, MUSM 720). Río Pescado (-10² 22' 48" S, -75 14' 24" W, MUSM 24198). San Juan

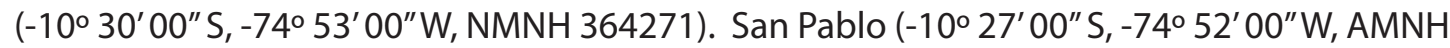
230130-230131, 230133-230136). SAN MARTIN: Rioja: Yaracyacu: Aguajal Rio mayo (-5 57' 00"S, -770 11'00"W, MUSM 35204-35206).

Gardnerycteris crenulatum crenulatum. BRASIL: AMAZONAS: Borba: Santo Antonio da Uayara, Río Madeira (-6 42'00"S, -69 52'00"W, AMNH 92223-92226, 92387-92388). Manaus: Igarape Cacao Pereira, Río Negro (-3॰09'00" S, -60 07'00"W, AMNH 79526). São Gabriel do Cachoeira:Taua, Río Vaupes (-3॰36'00"N,$-69^{\circ} 12^{\prime} 00^{\prime \prime} \mathrm{W}$, AMNH 78651-78658, 78832-78833). PARA: Belem: Mocambo-Embrapa (-10 45'00" S, -48 48' 20"W, FMNH 126211-126212).

Gardnerycteris crenulatum "Amazonía". COLOMBIA: Vaupes: Río Vaupes (AMNH 78652, 78655-78656, 78832-78833). PERÚ: LORETO: Alto Amazonas: Nuevo San Juan, Río Gálvez (-5० 15' 00" S, -730 10' 00" W, AMNH 272769-272770, 272834). Mariscal Ramón Castilla: Río

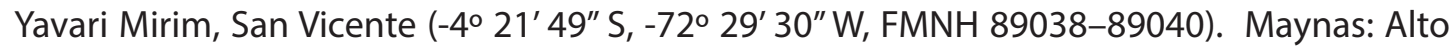

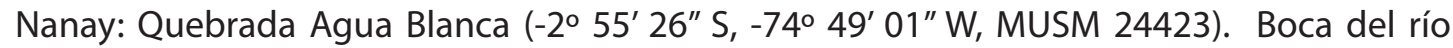

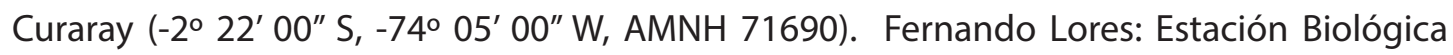

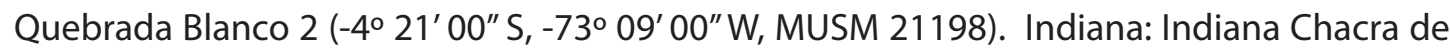
Clayder (-3 29'39"S, 73-2' 21"W, MUSM 32080-32081). Mazan: Sucusari, Quebrada Grande (-3० 15' 26" S, -72 55' 03" W, MUSM 21199). Punchana: Barrio Orosa Estación Madreselva II, río Amazonas (-3 37' 40" S, -72 14' 24" W, MUSM 32052-32053, 32055). Comunidad de Manacamiri, Río Nanay, Fundo Morropón (-3 42' 31"S, -73० 18'04"W, MUSM 28593). Iquitos

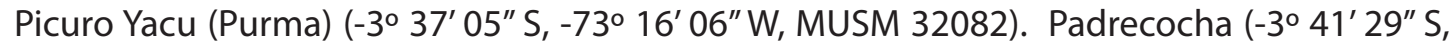
$-73^{\circ} 17^{\prime} 07^{\prime \prime}$ W, MUSM 28602). San Juan Bautista: 13 de Febrero, Fundo Nemith, E km 33 de

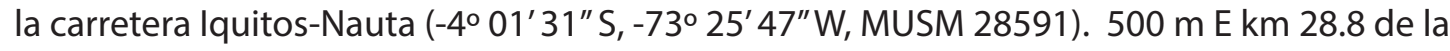

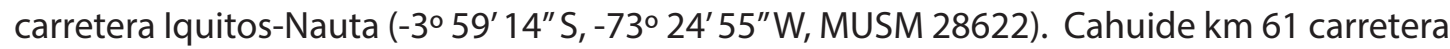
Iquitos-Nauta (-40 15' 46" S, -730 30'05" W, MUSM 32060). Camino a El Paujil, 1,8 km al W

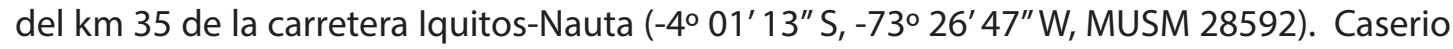
Cahuide Km 59 carretera lquitos-Nauta (-4o 14' 32" S, -730 29' 31" W, MUSM 32061-32065).

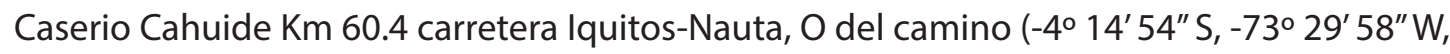

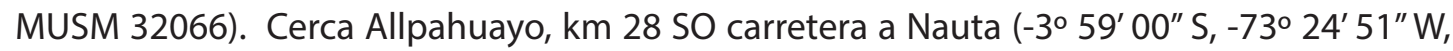
MUSM 32067). Cerca de la Aldea, km 18 SO carretera a Nauta (-30 54' 16" S, -73० 22' 14" W, MUSM 32068-32069). El Dorado, km 25 de la carretera lquitos-Nauta, app. $1.5 \mathrm{~km}$ al E (-30 $\left.58^{\prime} 00^{\prime \prime} \mathrm{S},-73^{\circ} 23^{\prime} 37^{\prime \prime} \mathrm{W}, \mathrm{MUSM} 28594\right)$. El Triunfo Km 48 carretera lquitos-Nauta (-4 09' 02"S, $-73^{\circ} 28^{\prime} 03^{\prime \prime}$ W, MUSM 32070). Fundo Mery Rojas Km 19.7 carretera lquitos-Nauta, 10 min. NO (-3० 54' 48" S, -73० 22' 58"W, MUSM 32072-32073). Habanillo Km 53 carretera lquitos-Nauta (-40 11'30" S, -73० 28' 45"W, MUSM 32074-32079). La Habana Km 52 carretera lquitos-Nauta (-40 10' 52" S, -730 28' 52" W, MUSM 32083-32085). Moralillo, 1.5 km E 500 m S del km 15.2 de la carretera lquitos-Nauta (-3० 54' 23" S, -730 20'37" W, MUSM 28595, 28597). Ninarumi,

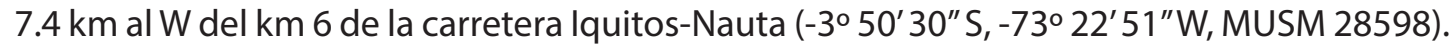
Ninarumi, $7.4 \mathrm{~km}$ al W y $1 \mathrm{~km}$ al SE del km 6 de la carretera lquitos-Nauta (-3० 50'59" S, $-73^{\circ}$ $22^{\prime} 26^{\prime \prime}$ W, MUSM 28599). Ninarumi, $7.4 \mathrm{~km}$ al W y $500 \mathrm{~m}$ al SE del km 6 de la carretera lquitosNauta (-3० 50' 44" S, -73० 22' 49" W, MUSM 28601). Paujil, W km 37.45 de la carretera lquitosNauta (-4 03' 32" S, -73० 26' 32"W, MUSM 28603-28606). Peña Negra, $600 \mathrm{~m}$ al W del km 10 de la carretera lquitos-Nauta (-30 51' 19" S, $-73^{\circ} 20^{\prime} 42^{\prime \prime}$ W, MUSM 28607, 28609). Peña Negra,

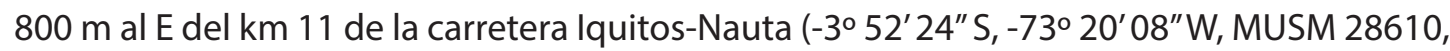
28612-28616). Peña Negra, Km 10 carretera lquitos-Nauta (-3॰ 51'14"S, -73²0'48"W, MUSM 
32095-32096). Puerto Almendra Arboretum de CEIFOR (-3 50' 20" S, -73² 22' 28" W, MUSM 32097). Quistocoha Km 5 carretera lquitos-Nauta, 1 km O del camino, Fundo Quistococha (-3० 49' 03" S, -73० 19' 55" W, MUSM 32101). San Juan, Avenida de la Participación (-3० 46' $43^{\prime \prime}$ S, $-73^{\circ} 16^{\prime} 44^{\prime \prime}$ W, MUSM 32102). San Lucas, W km 43 de la carretera lquitos-Nauta (-4º $06^{\prime} 15^{\prime \prime} \mathrm{S},-73^{\circ} 27^{\prime} 48^{\prime \prime} \mathrm{W}$, MUSM 28617-28618). Trece de febrero Km 31.5 carretera lquitosNauta, Estación de campo UNAP (-3 59' 59" S, -73 26' 31"W, MUSM 32103). Santo Tomás,

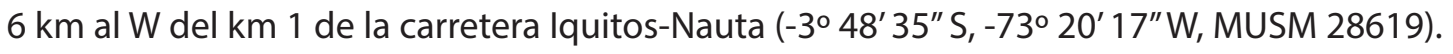

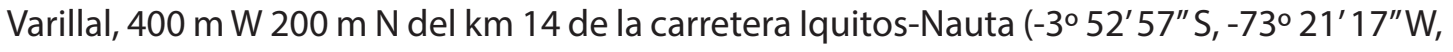
MUSM 28621). Torres Causana: Río Lagartococha, Campamento Catalino (00 31' 42" S, $-75^{\circ}$

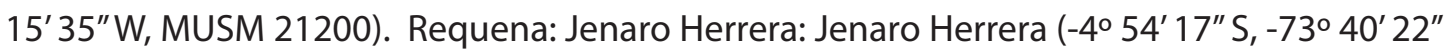

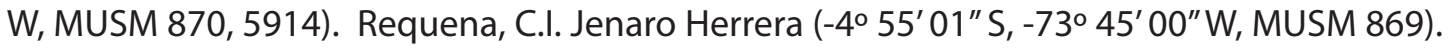
Ucayali: Contamana: Sierra de Contamana, Cerros de Canchaguaya, Aguas Calientes (070 11' 20" S, 74 56' 54" W, MUSM 17959). UCAYALI: Coronel Portillo: Yarinacocha (-8० 18' 00" S, -74º $36^{\prime} 00^{\prime \prime}$ W, FMNH 62120). Padre Abad: Irazola: Padre Abad, B.N. Von Humboldt (-8० 46' 59" S,

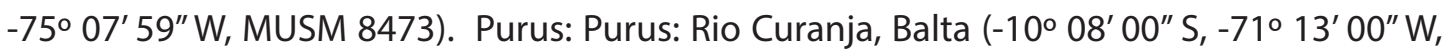
MUSM 1145). VENEZUELA: AMAZONAS: Atabapo: Mount Duida, Middle Camp $\left(3^{\circ} 25^{\prime} 00^{\prime \prime} \mathrm{N}\right.$, $\left.-65^{\circ} 40^{\prime} 00^{\prime \prime} \mathrm{W}, \mathrm{AMNH} 77524\right)$.

Gardnerycteris crenulatum "Guayanas". GUYANA FRANCESA: CAYENNE: Sinnamary: Paracou (4० 56'00" N, -52० 20' 00" W, AMNH 267109, 267111-267115, 267437, 267880267881, 267883-267884, 267886-267889). SURINAM: SIPALIWINI: Coeroeni: Kayser Gebergte Airstrip, East of Zuid River ( $3^{\circ} 07^{\prime} 00^{\prime \prime} \mathrm{N},-56^{\circ} 27^{\prime} 00^{\prime \prime} \mathrm{W}$, FMNH 93208). TRINIDAD Y TOBAGO: TRINIDAD: Nariva County: Bush Bush Forest, Nariva Swamp ( $10^{\circ} 23^{\prime} 00^{\prime \prime} \mathrm{N},-61^{\circ} 02^{\prime}$ 00"W, AMNH 119420-119421). Saint George County: Blanchisseusse, Las Cuevas (10 47'00"

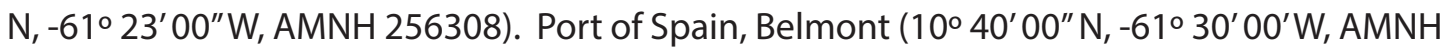
175586). Port of Spain (10॰39'00" N, -61 $\left.{ }^{\circ} 31^{\prime} 00^{\prime \prime} \mathrm{W}, \mathrm{AMNH} 207063\right)$.

Gardnerycteris crenulatum "Sur". BOLIVIA: BENI: Mamore: Boca del Río Baures (-12॰ 30' 00"S, -640 18' 00"W, AMNH 209323). PERÚ: CUSCO: La Convención: Echarate: Camisea (-110 $53^{\prime} 00^{\prime \prime} \mathrm{S},-72^{\circ} 39^{\prime} 00^{\prime \prime} \mathrm{W}, \mathrm{NMNH}$ 582790). La Convención, Camisea, Armihuari (-11 51'51"S, -72॰ 46' 46" W, MUSM 13738-13739). La Convención, Camisea, San Martín (-110 47' 00" S, $-72^{\circ} 42^{\prime} 00^{\prime \prime}$ W, MUSM 13740-13741). La Convención, Camisea, Segakiato (-11 50’ 42" S, -72。 35' 59" W, MUSM 14771). MADRE DE DIOS: Manu: Madre de Dios: Alto Rio Madre de Dios,

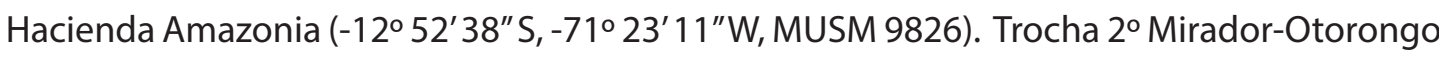

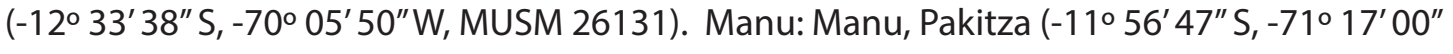
W, MUSM 479, 6791, 6792). 
Listado de sinapomorfías y autopomorfías a partir de optimizaciones. Las diagnosis se presentan de la siguiente manera: nombre del taxón o el número de nodo, carácter (número de carácter), número de estado -> número de estado (indica que el estado de la izquierda cambió al estado de la derecha).

Micronycteris megalotis: Sin autapomorfias.

Nodo 21: Sin sinapomorfías.

Nodo 34: Longitud de la hoja nasal (22): $2 \rightarrow$ 1; Forma de la hoja nasal (23): $0 \rightarrow$ 1; Forma del borde posterior de la caja craneana (51): $0 \rightarrow$ 2; Longitud del cráneo (54): $0 \rightarrow$ 1; Forma del borde posterior de la pre-maxila (60): 0 -> 2; Presencia de cíngulo lingual en el M2 (77): 1 -> 0; Longitud relativa del calcar (89): 0 -> 1; Longitud relativa de la cola (91): 1 -> 0.

Lophostoma occidentalis: Patrón de bandas de contraste del pelaje dorsal (2): 1 -> 2; Surco central del mentón (18): $1 \rightarrow 0$; Forma de las almohadillas al lado de la hoja nasal (21): $0 \rightarrow 2$; Grosor de la oreja (34): $0 \rightarrow$ 1; Pliegue en la base exterior de la oreja (38): $0 \rightarrow$ 1; Arreglo de pelos en el dorso de la pata (42): $1 \rightarrow 0$; Forma de los nostriles (44): $2 \rightarrow 1$; Forma del jugal (55): $2 \rightarrow$ 0; Forma de la bullas timpánicas (68): 1 -> 0; Compresión de los caninos inferiores (86): $1 \rightarrow 0$.

Nodo 33:Tamaño corporal (1): $1 \rightarrow 0$; Presencia de pelos en el antebrazo (16): $0 \rightarrow$; Forma del mentón (17): $1 \rightarrow$ 0; Forma de la rama intermedia del trago (28): $0 \rightarrow$ 1; Pigmentación en la punta de la alas (40): $1 \rightarrow 0$; Tamaño de la abertura del meato auditivo (69): $0 \rightarrow$; Forma del tabique del basiesfenoides (73): $1 \rightarrow 0$.

Tonatia saurophila: Longitud de la hoja nasal (22): $1 \rightarrow 0$; Forma de la rama principal del trago (27): $0 \rightarrow$ 1; Protuberancias en el lóbulo interno de la oreja (36): $0 \rightarrow$ 1; Disposición de las crestas de los incisivos (47): $1 \rightarrow$ 2; Perfil de la caja craneana (50): $1 \rightarrow$ 0; Amplitud de la constricción postorbital (56): $1 \rightarrow 0$; Forma del piso del paladar (58): $1 \rightarrow 0$; Forma del borde posterior de la pre-maxila (60): $2 \rightarrow$; Amplitud del tabique medio en la pre-maxila (61): 0 $\rightarrow 1$.

Nodo 32: Forma de las almohadillas al lado de la hoja nasal (21): $0 \rightarrow$ 1; Pigmentación en la hoja nasal (25): 1 -> 0; Pigmentación de la planta de la pata (41): $1 \rightarrow$ 0; Amplitud de los bordes laterales del paladar (64): $2 \rightarrow 1$; Número de lóbulos de los incisivos inferiores internos (i1) (83): $0 \rightarrow$ 1; Presencia de glándula accesoria y cuerpo blanco masculinos (129) - Carácter 130 de Wetterer et al. (2000): 1 -> 0.

Trachops cirrhosus: Densidad de los pelos en el hocico (7): $1 \rightarrow 0$; Pigmentación de la oreja (33): 1 -> 0; Forma del perfil del rostro (45): $0 \rightarrow$ 1; Disposición de las crestas de los incisivos (47): $1 \rightarrow$ 0; Forma de la raíz maxilar del cigoma (49): $0 \rightarrow$ 1; Presencia del proceso posterior del paladar (65): $0 \rightarrow$ 1; Alcance de la fosa mesopterigoidea (66): $1 \rightarrow$ 0; Compresión de los caninos inferiores (86): $1 \rightarrow 0$.

Nodo 31: Patrón de bandas de contraste del pelaje dorsal (2): $1 \rightarrow 2$; Surco central del mentón (18): 1 -> 2; Desarrollo del lóbulo interno de la oreja (37): $0 \rightarrow$ 1; Forma de los nostriles (44): $2 \rightarrow 3$; Forma del borde posterior de la caja craneana (51): $2 \rightarrow 0$; Forma del jugal (55): 2 $\rightarrow$ 0; Forma de la bullas timpánicas (68): $1 \rightarrow 0$; Forma de la base posterior de la mandíbula (81): $1 \rightarrow 2$.

Nodo 35: Longitud del pelaje dorsal (4): $0 \rightarrow$ 2; Presencia de pelos en el antebrazo (16): $1 \rightarrow$ 0; Tamaño de la oreja (30): $2 \rightarrow$ 0; Forma del borde de la oreja (35): $1 \rightarrow$ 0; Perfil de la caja craneana (50): 1 -> 0; Longitud relativa de la caja craneana (53): $1 \rightarrow 0$; Amplitud de la 
constricción postorbital (56): 1 -> 0; Posición del foramen accesorio medio (62): 1 -> 0; Forma del tabique del basiesfenoides (73): $0 \rightarrow 1$.

Phyllostomus discolor: Forma del mentón (17): $0 \rightarrow$ 1; Pigmentación en la hoja nasal (25): $0 \rightarrow 1$; Forma del borde inferior de la herradura (26): $1 \rightarrow 0$; Forma de la rama principal del trago (27): $0 \rightarrow 1$; Forma de la rama intermedia del trago (28): $1 \rightarrow 2$; Pliegues paralelos de la oreja (32): 1 -> 0; Pigmentación en la punta de la alas (40): $0 \rightarrow$ 1; Pigmentación de la planta de la pata (41): $0 \rightarrow$ 1; Forma de borde posterior de la caja craneana (51): $0 \rightarrow$ 1; Forma del jugal (55): $0 \rightarrow 1$; Alcance de la fosa mesopterigoidea (66): $1 \rightarrow 0$; Profundidad de la cavidades del basiesfenoides (72): $2 \rightarrow 0$; Arreglo del tercer y quinto metacarpal (88): $2 \rightarrow 0$; Tipo de cobertura con papilas en la región faríngea de la lengua (113) - Carácter 111 de Wetterer et al. (2000): $1 \rightarrow 0$.

Phylloderma stenops: Densidad del pelaje corporal (6): $1 \rightarrow 0$; Número de vibrisas interramales (9): $0 \rightarrow 2$; Ornamentaciones de pelos en el mentón (19): $1 \rightarrow$ 0; Forma de la raíz maxilar del cigoma (49): 0 -> 2; Forma del piso del paladar (58): 1 -> 2; Ubicación de la pre-maxila en el paladar (59): $0 \rightarrow$ 1; Presencia de cíngulo lingual en el M2 (77): $0 \rightarrow$ 1; Compresión de los caninos inferiores (86): $1 \rightarrow 0$.

Nodo 30: Número de vibrisas laterales a la hoja nasal (8): 1, o $2 \rightarrow 3$;

Arreglo de vibrisas laterales a la hoja nasal (10): 1 -> 0; Disposición de papilas submentales (20): $0 \rightarrow 1$; Forma de la rama intermedia del trago (28): $1 \rightarrow 0$; Forma de la rama interior del trago (29): 1, o $2 \rightarrow 0$; Grosor de la oreja (34): $0 \rightarrow$ 1; Protuberancias en el lóbulo interno de la oreja (36): $0 \rightarrow 1$; Pliegue en la base exterior de la oreja (38): $0 \rightarrow$ 1; Tamaño relativo del paladar (57): $0 \rightarrow$ 1; Presencia de par de cavidades detrás de los incisivos (63): $0 \rightarrow 1$.

Mimon bennettii: Posición del foramen accesorio medio (62): $1 \rightarrow 2$;

Forma de la fosa mesoterygoidea (67): $0 \rightarrow 1$; Tamaño de la abertura del meato auditivo (69): $1 \rightarrow 0$.

Mimon cozumelae: Amplitud del tabique medio en la pre-maxila (61): $0 \rightarrow 1$.

Nodo 20: Densidad de los pelos en el hocico (7): $1 \rightarrow 0$; Longitud de los pelos al contorno de la hoja nasal (11): 0 -> 3; Surco central del mentón (18): 1 -> 2; Ornamentaciones de pelos en el mentón (19): $1 \rightarrow$ 0; Pigmentación en la hoja nasal (25): $2 \rightarrow$ 1; Forma del borde inferior de la herradura (26): $1 \rightarrow 0$; Forma de la rama intermedia del trago (28): $0 \rightarrow$ 2; Pigmentación de la oreja (33): $1 \rightarrow$ 0; Protuberancias en el lóbulo interno de la oreja (36): $0 \rightarrow$ 1; Arreglo de pelos en el dorso de la pata (42): $1 \rightarrow 2$; Forma del perfil del rostro (45): $0 \rightarrow 1$. Amplitud del tabique medio en la pre-maxila (61): $0 \rightarrow$ 1; Presencia del premolar inferior p3 (84): $1 \rightarrow 0$; Número de papilas centrales callosas (123) - Carácter 124 de Wetterer et al. (2000): $0 \rightarrow 1$.

Mimon koepckeae: Forma de los nostriles (44): $2 \rightarrow 0$; Longitud relativa de la caja craneana (53): $1 \rightarrow 0$; Alcance de la fosa mesopterigoidea (66): $1 \rightarrow 0$; Amplitud del basioccipital a la altura de las cocleas (70): $0 \rightarrow 1$.

Nodo 25: Forma de borde posterior de la caja craneana (51): $0 \rightarrow 1$; Forma del borde posterior de la pre-maxila (60): $0 \rightarrow 1$; Forma de la fosa mesoterygoidea (67): $0 \rightarrow 1$; Forma de la bullas timpánicas (68): $1 \rightarrow 3$; Forma del tabique del basiesfenoides (73): $1 \rightarrow 0$; Forma de la base posterior de la mandíbula (81): $1 \rightarrow 0$; Número de lóbulos de los incisivos inferiores internos (i1) (83): $0 \rightarrow 1$.

Nodo 28: Forma de las almohadillas al lado de la hoja nasal (21): $0 \rightarrow$ 1; Pigmentación en la punta de la alas (40): $1 \rightarrow 0$; Forma del perfil del rostro (45): $1 \rightarrow 2$; Compresión del premolar cuatro inferior p4 (87): $1 \rightarrow 0$. 
Mimon crenulatum keenani "Venezuela": Surco central del mentón (18): 2 -> 1.

Nodo 27: Pigmentación en la hoja nasal (25): 1 -> 0.

Mimon crenulatum keenani "Panamá": Sin autapomorfias.

Nodo 29: Forma de las almohadillas al lado de la hoja nasal (21): $0 \rightarrow 1$

Mimon crenulatum keenani "Tumbes": Profundidad de la cavidades del basiesfenoides (72): 1 -> 0.

Mimon crenulatum keenani "Ecuador": Número de vibrisas laterales a la hoja nasal (8): 2 -> 1; Longitud de los pelos al contorno de la hoja nasal (11): $3 \rightarrow$ 2; Compresión de los caninos inferiores (86): $1 \rightarrow 0$.

Nodo 24: Patrón de bandas de contraste del pelaje dorsal (2): $1 \rightarrow 0$; Longitud de los pelos al contorno de la hoja nasal (11): $3 \rightarrow$ 2; Longitud de la hoja nasal (22): $2 \rightarrow 3$; Forma del borde de la oreja (35): $1 \rightarrow 0$; Desarrollo de la cresta sagital (52): $0 \rightarrow$ 1; Surco entre el hipocono y paracono del M1 y M2 (76): 1 -> 0; Compresión de los caninos inferiores (86): 1 -> 0; Arreglo del tercer y quinto metacarpal (88): $2 \rightarrow 1$.

Mimon crenulatum "Sur": Pigmentación en la hoja nasal (25): $1 \rightarrow 0$; Perfil de la caja craneana (50): $1 \rightarrow$ 0; Forma de borde posterior de la caja craneana (51): 1 -> 2; Amplitud del basioccipital a la altura de las cócleas (70): $0 \rightarrow 1$.

Nodo 23: Forma de la rama principal del trago (27): $0 \rightarrow$ 1; Tamaño de la oreja (30): $1 \rightarrow 0$; Longitud relativa de la caja craneana (53): $1 \rightarrow 0$; Forma de la bullas timpánicas (68): $3 \rightarrow$ 2; Profundidad de la cavidades del basiesfenoides (72): $1 \rightarrow 0$.

Mimon crenulatum longifolium: Longitud de los pelos al contorno de la hoja nasal (11): 2 $\rightarrow$ 1; Crenulaciones al borde la hoja nasal (24): 3 -> 2; Forma del tabique del basiesfenoides (73): $0 \rightarrow 1$; Longitud del proceso angular de la mandíbula (80): $0 \rightarrow 1$; Longitud relativa del calcar (89): $0 \rightarrow 1$.

Nodo 22: Longitud del pelaje dorsal (4): $1 \rightarrow$ 2; Número de vibrisas laterales a la hoja nasal (8): $2 \rightarrow 1$; Surco central del mentón (18): $2 \rightarrow 1$; Forma de la rama intermedia del trago (28): 2 $\rightarrow 1$; Protuberancias en el lóbulo interno de la oreja (36): 1 -> 0; Amplitud del tabique medio en la pre-maxila (61): $1 \rightarrow 0$; Arreglo del tercer y quinto metacarpal (88): $1 \rightarrow 0$.

Mimon crenulatum crenulatum: Sin autapomorfias.

Nodo 26: Arreglo de pelos en el dorso de la pata (42): $2 \rightarrow$; Forma del borde posterior de la pre-maxila (60): $1 \rightarrow 0$.

Mimon crenulatum "Amazonia": Forma de la rama principal del trago (27): $1 \rightarrow 0$; Tamaño de la abertura del meato auditivo (69): $0 \rightarrow 1$.

Mimon crenulatum "Guayanas": Longitud de los pelos al contorno de la hoja nasal (11): 2 $\rightarrow 1$; Forma del tabique del basiesfenoides (73): $0 \rightarrow 1$. 
ANÁLISIS FILOGENÉTICO DE MIMON

792 THERYA Vol.5(3): 751-791 